\title{
American Gastroenterological Association Technical Review on the Management of Barrett's Esophagus
}

\author{
STUART J. SPECHLER \\ VA North Texas Health Care System and the University of Texas Southwestern Medical Center \\ Dallas, Texas
}

PRATEEK SHARMA

VA Kansas City and the University of Kansas Medical Center

RHONDA F. SOUZA

VA North Texas Health Care System and the University of Texas Southwestern Medical Center Dallas, Texas

JOHN M. INADOMI

Division of Gastroenterology Department of Medicine University of Washington School of Medicine Seattle, Washington

NICHOLAS J. SHAHEEN

Center for Esophageal Diseases and Swallowing University of North Carolina at Chapel Hill Chapel Hill, North Carolina

\section{American Gastroenterological Association Institute Process for Development of Technical Reviews}

The aim of evidence-based medicine is to improve the quality of health care by integrating the best research evidence with clinical expertise and patient values. Evidence-based clinical guidelines are sets of recommendations intended to assist health care providers and patients in selecting the best management for common clinical situations while accounting for patient-specific circumstances. In addition to providing optimal, patient-centered care and improved outcomes, guidelines can reduce practice variability, identify gaps in evidence, enhance efficiency of resource use, and facilitate development of outcome and performance measures.

The American Gastroenterological Association Institute (AGAI) Medical Position Statement Procedure Manual, released in 2007, endorses the 2003 version of the US Preventive Services Task Force system to grade strength of recommendations. Although an excellent standard for producing recommendations regarding preventive services, the US Preventive Services Task Force has limitations when used to assess interventions that are not based on

\footnotetext{
(C) 2011 The American Gastroenterological Association. Published by Elsevier Inc. Allrights reserved

Reprint requests Address requests for reprints to: Chair, Clinical Practice and Quality Management Committee, AGA National Office, 4930 Del Ray Avenue, Bethesda, Maryland 20814. sagyeman@ @astro.org; telephone: (301) 272-1189.

Publisher's Disclaimer: This is a PDF file of an unedited manuscript that has been accepted for publication. As a service to our customers we are providing this early version of the manuscript. The manuscript will undergo copyediting, typesetting, and review of the resulting proof before it is published in its final citable form. Please note that during the production process errors may be discovered which could affect the content, and all legal disclaimers that apply to the journal pertain.

Conflicts of interest The authors disclose the following: Dr Souza is a consultant for Ironwood Pharmaceuticals and is a consultant for and receives grant support from AstraZeneca. Dr Inadomi is a consultant for Takeda Pharmaceuticals, AstraZeneca, and Ethicon Endo-Surgery, Inc. Dr Spechler, Dr Sharma, and Dr Shaheen disclose no conflicts.
} 
prevention. The Grading of Recommendations Assessment, Development and Evaluation (GRADE) system (http://www.gradeworkinggroup.org/index.htm) has been adopted by several national and international societies and was constructed to address the shortcomings of existing grading systems, including the US Preventive Services Task Force system. GRADE separates quality of evidence from the strength of recommendation to ensure that the magnitude of benefits and harms is assessed as rigorously as the efficacy of interventions. With regard to strength of recommendations, GRADE has 2 categories: strong and weak (Table 1). Strong recommendations are meant to signify interventions that should be received by most individuals with a particular condition and can be adopted as policy in most circumstances. Weak recommendations require individualized scrutiny of the evidence and policy making would require substantial debate and involvement from multiple stakeholders. The classification requires consideration of 4 factors: quality of evidence, uncertainty about the balance between desirable and undesirable effects, variability in values and preferences, and uncertainty about whether the intervention represents a wise use of resources (Table 2). Of importance to our current health care debate is that interventions receiving a strong recommendation may be targets for development of performance measures.

Quality of evidence is assessed on a 4-point scale: high, moderate, low, and very low. Instead of being classified strictly on the basis of study design (ie, randomized, controlled clinical trials automatically receiving "high" quality marks), these levels reflect the likelihood that further research would change our confidence in the estimate of the beneficial effect of a particular intervention. Five factors that determine quality include study limitations, inconsistency of results between studies, indirectness (generalizability) of results, imprecision, and publication bias. For this reason, randomized, controlled clinical trials that have methodological flaws may be downgraded, whereas well-done observational studies that have large effect sizes (ie, relative risk $[R R]>2-5$ or $<0.5-0.2$ ) may be upgraded.

\section{AGAI Procedure for Construction of Technical Reviews}

The AGAI Clinical Practice and Quality Management Committee (CPQMC) chooses a topic by consensus discussion, votes after reviewing a list of potential topics derived from AGAI member recommendations, and develops the specific questions the guideline will answer. The CPQMC committee chair, with support of AGA staff, then contacts the AGAI clinical counsel chair and requests the input of the counsel for authorship and external reviewers.

Authors are selected and write a technical review (TR), which is an evidence-based document that provides the basis for clinical practice recommendations. For each of the specific questions raised by the CPQMC, authors conduct an independent systematic review of the literature using published guidelines (PRISMA). Articles selected for inclusion in the TR are based on a priori inclusion and exclusion criteria agreed on by all authors. Data extraction is shared among TR authors, and the individual study and summary results are reviewed and approved by all authors. The search terms for each topic included in the TR are included in the Appendix. It is not the function of the TR to provide a summary estimate for each variable included in the review. For this reason, results are summarized in the text of the TR and not subjected to a formal meta-analysis. The draft TR is compiled by the lead author and approved by all authors before submission for publication.

A medical position panel composed of the TR authors, additional content experts, practicing gastroenterologists, other specialists (eg, surgeon, pathologist), a patient representative, a payer representative, and American Gastroenterological Association staff meet through a series of face-to-face and telephone meetings to construct the medical position statement, 
which is based on the TR but also reflects these discussions by the medical position panel. The medical position panel approves the medical position statement, after which this document and the TR are reviewed by the CPQMC. Based on the vote of the committee, a recommendation is submitted to the AGAI Governing Board, which provides final approval. When approval is granted, the medical position statement is published in $\mathrm{G}_{\text {ASTROENTERoLOGY }}$ and is also posted on the American Gastroenterological Association web site.

The objectives of the AGAI TR on the management of patients with Barrett's esophagus were to evaluate diagnostic and management strategies for patients at risk for or diagnosed with Barrett's esophagus. Specifically, 10 broad questions were developed by interaction among the authors, the AGAI, the Clinical Practice and Quality Management Committee, and representatives from the AGAI Council. The questions were designed to encapsulate the major management issues leading to consultations for Barrett's esophagus and esophageal adenocarcinoma in clinical practice in 2010. For each question, a comprehensive literature search was conducted, pertinent evidence reviewed, and a summary of relevant data produced. The conclusions of this review were based on the best available evidence or, in the absence of quality evidence, the expert opinion of the authors of the TR.

\section{What Is the Definition of Barrett's Esophagus? What Landmark Identifies the Gastroesophageal Junction? What Epithelial Type Is Required for the Diagnosis of Barrett's Esophagus? Should Endoscopists Measure the Extent of Barrett's Metaplasia?}

Authorities generally have defined Barrett's esophagus conceptually as the condition in which metaplastic columnar epithelium replaces the stratified squamous epithelium that normally lines the distal esophagus. ${ }^{1-4}$ Unfortunately, this deceptively simple conceptual definition does not translate readily into clinically useful diagnostic criteria for 2 major reasons. (1) There are no universally accepted, precise, and validated landmarks that delimit the distal extent of the esophagus (ie, that identify the gastroesophageal junction [GEJ]). If it cannot be determined precisely where the esophagus ends and the stomach begins, then it may not be possible to ascertain the type of epithelium that lines the most distal esophagus. (2) There is no way to verify that gastric-type columnar epithelia found in the distal esophagus are metaplastic. These 2 factors become major confounders when attempting to establish a diagnosis of Barrett's esophagus for patients with only short segments of esophageal columnar epithelium.

What Landmark Identifies the Gastroesophageal Junction?-The diagnosis of Barrett's esophagus can be suspected when, during endoscopic examination, columnar epithelium (which has a characteristic endoscopic appearance) is observed to extend above the GEJ into the esophagus. Of course, this diagnostic suspicion is based on the assumption that the endoscopist can identify the GEJ. Few studies have addressed specifically the issue of how to localize the GEJ, and even those that have the accuracy of the criteria used cannot be assessed meaningfully in the absence of a validated landmark (ie, a gold standard).

Western endoscopists generally identify the GEJ as the most proximal extent of the gastric folds, a landmark first proposed in 1987 in a report of a small and methodologically flawed study. ${ }^{5}$ The location of the proximal extent of the gastric folds is affected by respiration, gut motor activity, and the degree of distention of the esophagus and stomach, all of which can change from moment to moment. Endoscopists in Asia often use the distal extent of the palisade vessels, which are fine longitudinal veins located in the lamina propria of the distal esophagus, as their landmark for the GEJ. ${ }^{6,7}$ The palisade vessels can be obscured by esophagitis, their level of termination can be irregular and difficult to localize with precision, and conceptually it is not clear why the distal end of the palisade vessels should 
be considered the end of the esophagus. Thus, the scientific validity of the 2 most widely used landmarks for the GEJ is dubious.

The issue of the "best" landmark for the GEJ is likely to remain controversial indefinitely because, ultimately, the choice of any such landmark will be arbitrary. The majority of published studies on Barrett's esophagus conducted over the past 20 years have used the proximal extent of the gastric folds as the landmark for the GEJ and, in the absence of compelling data for the use of alternative markers, we presently recommend the continued use of this landmark despite its shortcomings.

\section{What Epithelial Type Is Required for a Diagnosis of Barrett's Esophagus?-}

Barrett's esophagus is judged to develop through the process of metaplasia in which one adult cell type replaces another. For reasons that are not clear, Barrett's metaplasia is predisposed to cancer development. Three types of columnar epithelia have been described in Barrett's esophagus: (1) a gastric fundic-type epithelium that has mucus-secreting cells, parietal cells, and chief cells; (2) a cardia-type (also known as junctional-type) epithelium composed almost exclusively of mucus-secreting cells; and (3) an intestinal-type epithelium (sometimes called specialized columnar epithelium or specialized intestinal metaplasia) that contains prominent goblet cells. ${ }^{8}$ The fundic- and cardia-type epithelia in Barrett's esophagus can be morphologically indistinguishable from columnar epithelia found in the stomach.

If biopsy specimens of suspected Barrett's esophagus reveal only fundic- and cardia-type epithelia, then it can be difficult to establish that those epithelial types are metaplastic because (1) biopsy sampling error can result in inadvertent biopsy of the stomach instead of the esophagus, especially when only short segments of columnar epithelium appear to extend above the GEJ, and (2) some authorities have argued that the normal distal esophagus can have short segments of a gastric-type columnar lining. ${ }^{9}$ With no precise landmark for the GEJ, it is difficult to support or refute that contention. If biopsy specimens of suspected Barrett's esophagus reveal intestinal-type epithelium, in contrast, then there is little doubt that the epithelium is abnormal and metaplastic. This finding does not obviate the issue of biopsy sampling error, however, because intestinal metaplasia is common in the stomach that is chronically infected with Helicobacter pylori. ${ }^{10}$

Intestinal-type epithelium can be readily identified by the pathologist and, unlike the gastrictype epithelia, intestinal-type epithelium is clearly abnormal when located in the esophagus. Furthermore, early reports suggested that the intestinal-type epithelium in Barrett's esophagus was the one predisposed to malignancy. For those reasons, practical more than scientific or conceptual, investigators and clinicians adopted the policy of requiring the demonstration of intestinal metaplasia in esophageal biopsy specimens as a sine qua non for the diagnosis of Barrett's esophagus. However, recent findings have challenged the validity of that practice. There are data to suggest that cardia-type epithelium may not be normal, but rather may be a metaplastic lining that develops as a consequence of chronic gastroesophageal reflux disease (GERD). ${ }^{11}$

Histochemical and genetic studies of cardia-type epithelium have revealed molecular abnormalities, similar to those found in specialized intestinal metaplasia, that may predispose to cancer development. ${ }^{12,13}$ Recent clinical studies also suggest that cardia-type epithelium has malignant potential. In one such study of 141 patients who underwent endoscopic mucosal resection (EMR) for small esophageal adenocarcinomas, $71 \%$ had cardia-type epithelium, not intestinal metaplasia, found adjacent to the cancer, and $57 \%$ had no intestinal metaplasia whatsoever found in the EMR specimen. ${ }^{14}$ 
The columnar-lined esophagus has clinical importance only because it predisposes to the development of esophageal cancer. The debate about whether patients who have only cardiatype epithelium lining the distal esophagus have "Barrett's esophagus" is primarily a semantic issue. The key unanswered clinical question for those patients is this: What is the risk of developing esophageal cancer? The great majority of studies on the risk of cancer in Barrett's esophagus have included patients with specialized intestinal metaplasia either primarily or exclusively. ${ }^{15}$ Although recent data suggest that cardia-type epithelium may well predispose to malignancy, the magnitude of that risk is not yet clear. A reasonable estimate of cancer risk is needed to make rational management decisions for patients with Barrett's esophagus, and no such estimate is available for patients who have only cardia-type epithelium in their columnar-lined esophagus.

Despite reasonable arguments supporting the concept that Barrett's esophagus might be defined by the presence of cardia-type as well as by intestinal-type epithelium in the esophagus, there are substantial practical reasons for not adopting this definition into clinical practice at this time. The inclusion of patients with cardia-type epithelium under the rubric of "Barrett's esophagus" would substantially increase the number of patients with that disorder, which would substantially increase treatment costs. The benefits of surveillance and treatment programs for Barrett's esophagus are debated, even for patients with intestinal metaplasia, whose cancer risk is far better defined. The likelihood of finding intestinal-type epithelium in Barrett's esophagus varies directly with the extent of the esophageal columnar lining, and the issue of whether to consider cardia-type epithelium a marker for Barrett's esophagus usually concerns only patients with short segments of esophageal columnar epithelium (generally segments considerably less than $3 \mathrm{~cm}$ in extent). The clinical benefit of biopsy sampling for patients with such short segments of esophageal columnar epithelium has not been established.

What Is the Definition of Barrett's Esophagus?-Any definition of Barrett's esophagus necessarily will have an arbitrary component. If Barrett's esophagus is to be considered a medical condition rather than merely an anatomic curiosity, then it should have clinical importance. The columnar-lined esophagus has clinical importance only if it predisposes to esophageal cancer. Therefore, we believe that Barrett's esophagus can be defined conceptually as the condition in which any extent of metaplastic columnar epithelium that predisposes to cancer development replaces the stratified squamous epithelium that normally lines the distal esophagus. Presently, intestinal metaplasia is the only one of the 3 types of esophageal columnar epithelia described that clearly predisposes to malignancy; therefore, we suggest that the term "Barrett's esophagus" presently should be used only for patients who have intestinal metaplasia in the esophagus. Circumstantial evidence suggests that cardia-type epithelium also may be predisposed to cancer development, but presently that predisposition has not been established and there are insufficient data to make meaningful recommendations regarding the management of patients who have a columnar-lined esophagus with cardia-type epithelium alone. If future studies establish a malignant predisposition for cardia-type epithelium, then those patients also can be considered to have Barrett's esophagus by our proposed definition. For now, however, only patients with intestinal-type columnar metaplasia in the esophagus are known to have an increased cancer risk, and only those patients meet our criteria for the diagnosis of Barrett's esophagus.

Should Endoscopists Measure the Extent of Barrett's Metaplasia?-Barrett's esophagus has been categorized as long segment (when the metaplastic epithelium extends at least $3 \mathrm{~cm}$ above the GEJ) or short segment (when there is $<3 \mathrm{~cm}$ of metaplastic epithelium lining the esophagus). ${ }^{16}$ Another more recently proposed system for categorizing Barrett's esophagus, the Prague $\mathrm{C}$ and $\mathrm{M}$ criteria, identifies both the circumferential extent 
(C) and the maximum extent (M) of Barrett's metaplasia. ${ }^{17}$ One study has shown excellent interobserver agreement among endoscopists using the Prague $\mathrm{C}$ and $\mathrm{M}$ criteria when columnar epithelium extends at least $1 \mathrm{~cm}$ above the GEJ but poor agreement for shorter segments of esophageal columnar lining. ${ }^{17}$

There may be clinical value in measuring the extent of Barrett's metaplasia visualized during endoscopic examination (ie, the distance between the GEJ and the squamocolumnar junction in the esophagus). Data suggest that the likelihood of finding intestinal metaplasia in the columnar-lined esophagus and the magnitude of the cancer risk vary directly with the extent of the metaplastic lining (see the following text). For patients found to have dysplasia in Barrett's esophagus, furthermore, the extent of metaplasia is a factor that may influence the choice among the therapeutic options (see the following text). Therefore, we advocate the use of a system, like the Prague $\mathrm{C}$ and $\mathrm{M}$ criteria, that provides information on the extent of Barrett's metaplasia. However, the clinical benefit of using any proposed endoscopic system for classifying Barrett's esophagus has not been established by formal investigation and, presently, patients with any extent of intestinal metaplasia are managed similarly.

\section{What Is the Risk of Esophageal Cancer for the General Population of Patients With Barrett's Esophagus?}

A number of older reports linking Barrett's esophagus to esophageal adenocarcinoma described an inordinately high incidence of cancer, in the range of 20 to 40 per 1000 personyears (2\%-4\% per year). ${ }^{18-20} \mathrm{~A}$ variety of confounding factors, including selection bias, the inclusion of prevalent cancers, and publication bias, may have contributed to the overestimation of cancer risk in those studies. ${ }^{15}$ Subsequent reports of larger series generally have described a substantially lower cancer risk for patients with Barrett's esophagus, but even some modern reports describe very high cancer incidence rates. ${ }^{21}$ National health statistics cannot be used to estimate cancer risk because the denominator (ie, the total number of persons with Barrett's esophagus in the general population) is not known. Nevertheless, a reasonable estimate of the incidence of cancer in Barrett's esophagus is needed to formulate rational management strategies for patients with this condition.

A number of systematic reviews of studies on the incidence of cancer in patients with Barrett's esophagus have been published. ${ }^{15,22-24}$ A recent review described outcomes for 47 studies that met inclusion criteria from an initial search that yielded 7780 publications from MEDLINE and EMBASE databases (years 1950-2006). ${ }^{24}$ The overall estimate of cancer incidence was based on 209 cancers discovered in 11,279 patients with Barrett's esophagus who were followed up for 47,496 person-years. The average incidence of cancer was 6.1 per 1000 person-years, but this estimate may have been spuriously high because it included patients in whom cancer was discovered within the first year after the diagnosis of Barrett's esophagus. Such patients likely had prevalent cancers that were missed on their initial endoscopic examinations. After adjusting the results to exclude those patients, the incidence of cancer was 5.3 per 1000 person-years ( $0.5 \%$ per year), an estimate well aligned with the results of prior systematic reviews.

Among 4 studies published since the aforementioned systematic review was a report of a cohort of 502 patients with Barrett's esophagus from Leeds in the United Kingdom. ${ }^{25}$ The annual incidence of cancer among patients who had Barrett's esophagus with specialized intestinal metaplasia was 16 per 1000 person-years (1.6\% per year). Another single-center cohort from Birmingham in the United Kingdom calculated an incidence of 3.1 per 1000 person-years ( $0.3 \%$ per year) based on 3 cancers diagnosed among 188 patients with Barrett's esophagus. ${ }^{26} \mathrm{~A}$ third study from the United Kingdom reported statistics from a multicenter national registry involving 738 patients with a combined follow-up of 3697 years. The overall annual incidence of esophageal adenocarcinoma was $0.5 \%(95 \%$ 
confidence interval [CI], 0.3-0.8). ${ }^{27}$ Finally, an endoscopic and pathology-based database in Spain was retrospectively examined to calculate a cancer risk in patients with Barrett's esophagus of 5.2 per 1000 person-years $(0.5 \%$ per year $){ }^{28}$

The risk of cancer in Barrett's esophagus appears to vary with the extent of esophageal metaplasia; therefore, patients with long-segment disease may have a higher incidence of adenocarcinoma than those with short-segment Barrett's esophagus. ${ }^{23}$ In the aforementioned Spanish cohort, for example, the annual risk of esophageal adenocarcinoma was $0.57 \%$ for patients with long-segment Barrett's esophagus compared with only $0.26 \%$ for patients with short-segment disease. ${ }^{28}$ The risk of cancer development also is lower in women than in men with Barrett's esophagus (4.5 vs 10.2 cancers per 1000 person-years). ${ }^{24}$

The precise risk of cancer in Barrett's esophagus remains unclear. Reported estimates of cancer risk continue to vary widely, and it is not clear how biases, statistical aberrations, and regional differences in incidence rates contribute to the disparities among the published reports. Methodologically, larger studies (ie, 500 or more person-years of observation) report lower cancer incidence rates than smaller studies, as do studies that represent population-based as opposed to referral-based cohorts. ${ }^{24}$ Estimates of cancer risk also are likely to be affected by the proportion of patients with short-segment Barrett's esophagus and women in the cohort. With these limitations in mind, most modern systematic reviews and large series suggest that the annual incidence of cancer for the general population of patients with Barrett's esophagus is approximately $0.5 \%$ per year. For patients with dysplasia in Barrett's epithelium, the risk of cancer is substantially higher (see the following text).

\section{Does Barrett's Esophagus Affect Life Expectancy? How Does a Diagnosis of Barrett's Esophagus Affect Quality of Life?}

Does Barrett's Esophagus Affect Life Expectancy?-A review of the literature reveals some contradictory results for studies assessing the impact of a diagnosis of Barrett's esophagus on life expectancy. In a population-based study in Northern Ireland, Anderson et al compared mortality rates for subjects with Barrett's esophagus with those for age- and sex-matched subjects in the general population. The investigators found no significant differences in overall mortality rates between the 2 groups. ${ }^{29}$ Although deaths from esophageal cancer were more common in the group with Barrett's esophagus, the total frequency of such deaths was so low that it had little effect on overall mortality. Another study that compared survival for subjects with Barrett's esophagus with survival for 2 control groups (the general population and patients with Schatzki's rings) also found no difference in life expectancy among the groups. ${ }^{30}$ In contrast, Moayyedi et al in the United Kingdom found increased mortality for subjects who had Barrett's esophagus diagnosed at 4 hospitals in Leicestershire compared with age- and sex-matched subjects in the general population. ${ }^{31}$ Interestingly, however, the excess mortality in the patients with Barrett's esophagus was primarily due to extraesophageal diseases such as bronchopneumonia and ischemic heart disease. In another large population-based study in which survival for a cohort of 1677 patients with Barrett's esophagus was compared with an age- and sexmatched cohort of 13,416 individuals in the general population, Solaymani-Dodaran et al found that the patients with Barrett's esophagus had a $37 \%$ increase in mortality. ${ }^{32}$ Approximately $45 \%$ of the excess mortality in the patients with Barrett's esophagus was due to esophageal cancer, whereas 55\% was due to extraesophageal disorders such as cardiovascular disease. The excess deaths from cardiovascular problems may be related to the association of Barrett's esophagus with obesity, which also is a risk factor for cardiovascular disease.

Despite the somewhat disparate findings of these studies on survival for patients with Barrett's esophagus, several conclusions are warranted. First, even though deaths from 
esophageal adenocarcinoma are more common in patients with Barrett's esophagus than in individuals without that condition, adenocarcinoma remains an uncommon cause of mortality in patients with Barrett's esophagus nevertheless. ${ }^{33,34}$ Furthermore, because this cancer generally occurs later in life, ${ }^{35}$ the impact of such a death on the mean survival of the cohort is lessened, because deaths due to extraesophageal diseases such as cardiovascular disorders are far more common and therefore drive overall mortality rates. It also appears that mortality due to cardiovascular disease may be increased in patients with Barrett's esophagus, perhaps because of the association of the disorder with obesity.

\section{How Does a Diagnosis of Barrett's Esophagus Affect Quality of Life?-}

Numerous studies have attempted to quantify the quality of life in patients with Barrett's esophagus, but those studies are limited in several important ways. First, they lump all subjects with prevalent disease into a single category and compare that group with controls such as subjects who have GERD without Barrett's esophagus or the general population. It is likely that the quality of life for patients with Barrett's esophagus varies with a number of important factors, such as disease duration and the number of surveillance endoscopies performed, that are not accounted for in such studies. Second, the studies generally use a convenience sample of subjects with Barrett's esophagus attending outpatient clinics or endoscopy units at tertiary care centers. The impact of the disease on such subjects may be very different from that on the general population of individuals with Barrett's esophagus. For instance, one might expect subjects attending repeated endoscopic surveillance sessions to be more concerned about their risk of developing adenocarcinoma than those who forego such measures. Finally, there is no validated, disease-specific, widely accepted quality-oflife measure for Barrett's esophagus. Investigators have used generic quality-of-life measures as well as organ-specific measures and tools developed specifically for GERD populations. Those tools may fail to capture important domains of quality of life for subjects with Barrett's esophagus.

With these limitations in mind, a systematic review found 25 articles in the Englishlanguage literature that provide quantitative assessments of quality of life or financial and psychological burdens of disease for subjects with Barrett's esophagus. ${ }^{36}$ Five studies assessed patients using the generic quality-of-life measure 36-Item Short Form Health Survey (SF-36), ${ }^{37} 3$ studies used Quality of Life in Reflux and Dyspepsia (QOLRAD), ${ }^{38}$ and 2 studies used Gastrointestinal Quality of Life Index. ${ }^{39}$ Four studies evaluated utility measures in patients with Barrett's esophagus. Utilities rate the desirability of living with a given disease state on a scale of 0 to 1 , where a rating of 1 indicates essentially no decrease in the desirability of life and 0 indicates a quality of life so undesirable it is equal to death. Eight studies did not use traditional quality-of-life instruments but quantitatively assessed impact (psychological, financial, social, and so on) or burden of disease by other measures. Of these 25 studies, 9 included patients with Barrett's esophagus as a subset of patients with GERD symptoms or a priori compared patients with Barrett's esophagus with patients with GERD. The remaining 16 studies included only patients with Barrett's esophagus.

On balance, these studies show that a diagnosis of Barrett's esophagus has a substantial negative impact on quality of life. All reported cohorts showed lower SF-36 scores in subjects with Barrett's esophagus compared with the population norms. Studies using organspecific measures such as QOLRAD and Gastrointestinal Quality of Life Index also showed diminished quality of life in subjects with Barrett's esophagus compared with the population norms. One study found similar QOLRAD scores in patients with Barrett's esophagus and patients with GERD. Whereas both groups reported substantial GERD symptoms, it is possible that a major component of the decrease in quality of life experienced by the patients with Barrett's esophagus was due to their GERD symptoms. Attempts to quantify quality of life in Barrett's esophagus using health state utilities have repeatedly shown diminished 
utility for life with this condition. The negative impact on utility varies with the degree of dysplasia in Barrett's epithelium and has been reported to be as low as 0.77 for patients with high-grade dysplasia. ${ }^{40}$

Although subjects with Barrett's esophagus are consistently found to have a poorer quality of life than the general population, it is unclear to what extent this is attributable to anxiety regarding cancer risk, discomfort due to GERD symptoms, or other factors. Patients with Barrett's esophagus appear to greatly overestimate their cancer risk, and this overestimation is associated with an increase in their utilization of health care. ${ }^{41}$ In addition to this psychological distress, patients with Barrett's esophagus face higher individual costs for life insurance and may be unable to obtain health insurance. ${ }^{42}$

In summary, by generic and organ-specific quality-of-life measures, subjects with Barrett's esophagus repeatedly have been shown to have substantially lower scores than population norms. Subjects with Barrett's esophagus consistently report their utility of living with the disease lower than without it, and the decrease in utility correlates with the degree of dysplasia in Barrett's epithelium. A diagnosis of Barrett's esophagus appears to cause psychological stress and may be associated with substantial, but incompletely understood, additional costs such as increased life and health insurance premiums.

\section{Who Is at Risk for Barrett's Esophagus? Who Should Be Screened for Barrett's Esophagus?}

Who Is at Risk for Barrett's Esophagus?-A systematic review of original literature on the epidemiology of Barrett's esophagus shows that most published studies describe hospital-based or endoscopy clinic-based cohorts; relatively few describe large populationbased cohorts. It is important to consider this potential bias when assessing those epidemiologic studies, which have identified a number of risk factors for Barrett's esophagus. Selected risk factors are reviewed briefly in the following text.

It is not clear when Barrett's esophagus develops, but most recognized cases are diagnosed in the sixth decade of life or later. ${ }^{43,44}$ Although the utilization of endoscopy (and hence the chance of finding Barrett's esophagus) is higher in older subjects, cohort studies suggest that, as age increases, so does the likelihood that a subject with GERD symptoms will have Barrett's esophagus. ${ }^{43}$ Whether the condition results from a single catastrophic insult to the esophageal mucosa, which may be more likely to occur in older subjects, or whether Barrett's esophagus is the cumulative result of years of reflux-induced damage is not clear. Longitudinal studies, which have found that the extent of Barrett's metaplasia does not increase with time (at least in subjects on therapy), provide some support for the concept that the condition develops all at once. ${ }^{45}$

There is a male predominance for Barrett's esophagus, as there is for esophageal adenocarcinoma. In case-control and cohort studies, the risk of Barrett's esophagus among men with GERD symptoms is 1.5 - to 3-fold higher than that of women. ${ }^{44,46-48} \mathrm{~A}$ recent meta-analysis of cohort studies comprising consecutively enrolled subjects with Barrett's esophagus shows a case mix of men and women of approximately $2: 1{ }^{49}$ Whether this male preponderance is the result of differences between men and women in hormonal effects on the esophagus, body fat distribution, or other as-yet unidentified factors is not clear.

Most cohort studies show that the majority of subjects with Barrett's esophagus are white. ${ }^{48}$ Because most of these studies are clinic or hospital based, some of the apparent ethnic predisposition may be biased by the underlying demographics of the patients who attend those facilities. Several studies have attempted to quantify how the proportion of subjects with heartburn who have Barrett's esophagus varies among different ethnic groups. Abrams 
et al found that, among subjects who underwent endoscopy at their institution, white subjects were approximately 4 times as likely to have Barrett's esophagus as Hispanic or black subjects. ${ }^{43}$ Similarly, a cohort study of subjects presenting for screening colonoscopy who were invited to undergo upper endoscopy found that white subjects were more likely to have Barrett's esophagus than black subjects. ${ }^{50}$ In a community-based study, Corley et al found that the incidence of Barrett's esophagus in non-Hispanic white subjects was more than 6 times greater than that in black subjects. ${ }^{48}$ In contrast, Eloubeidi et al did not find race to be a predictor of Barrett's esophagus in a Veterans Administration population. ${ }^{51}$ If there are significant differences in the prevalence of Barrett's esophagus between white and black subjects, they are not likely the result of differences in the underlying prevalence of GERD, because the distribution of heartburn symptoms appears to be similar between those 2 groups. ${ }^{52}$ However, limited studies suggest that both GERD and Barrett's esophagus are far less common in Asian patients than in white subjects. ${ }^{53}$

GERD is strongly associated with Barrett's esophagus. Case-control studies suggest that subjects with heartburn are 6 to 10 times more likely to have Barrett's esophagus than those without heartburn. Furthermore, there appears to be a dose-response relationship in that subjects with more frequent or chronic GERD symptoms are more likely to have Barrett's esophagus. ${ }^{51,54-57}$ Hiatal hernia also is associated with the presence of Barrett's esophagus. ${ }^{46,55}$ However, the relationship between GERD symptom severity and Barrett's esophagus is not as strong. ${ }^{51}$

Cohort and case-control studies assessing esophageal acid exposure in subjects who have GERD with and without Barrett's esophagus showed that those with Barrett's esophagus have, on average, greater acid exposure than those without and that the extent of Barrett's metaplasia correlates directly with the duration of esophageal acid exposure. ${ }^{55}$ Increased bile reflux (as estimated by a system that measures esophageal exposure to bilirubin) also has been documented in subjects with Barrett's esophagus, ${ }^{46,58}$ but the role of components of refluxate other than acid in the development of the condition remains controversial.

A high body mass index and an intra-abdominal distribution of body fat have been shown to be strong risk factors for Barrett's esophagus. Patients with Barrett's esophagus have, on average, a higher body mass index than either patients with GERD without Barrett's esophagus or general population controls. ${ }^{59-61}$ Interestingly, the distribution of body fat may be the key to this association. For any given body mass index, subjects with higher amounts of intra-abdominal obesity, manifest either radiographically or by increased waist-to-hip ratio measures, appear to have an increased risk of Barrett's esophagus. ${ }^{59,60,62}$ In fact, in a recent analysis of body anthropometry in subjects with Barrett's esophagus, body mass index was no longer an independent predictor of the disorder once waist-to-hip ratio was factored. ${ }^{62}$ Whether the increased risk associated with intra-abdominal obesity is due to mechanical or hormonal factors or a consequence of yet-undescribed factors is not known.

Alcohol and smoking are not nearly as strongly associated with Barrett's esophagus as they are with squamous cell cancer of the esophagus, and studies on the association of these habits with Barrett's esophagus have yielded inconsistent results. In a population-based study, Ronkainen et al showed that subjects who used tobacco or alcohol were approximately 3 times as likely to have Barrett's esophagus as subjects who did not. ${ }^{63}$ Other studies have found an association between either smoking ${ }^{44}$ or alcohol ${ }^{64}$ and Barrett's esophagus, whereas a number of investigations have not. ${ }^{65-67}$ In fact, recent data suggest that consumption of wine actually may protect against Barrett's esophagus. ${ }^{65,66} \mathrm{High}$ vegetable and fruit intake appear to diminish the risk of Barrett's esophagus, although the mechanism is not known. ${ }^{68,69}$ 
In summary, well-established risk factors for Barrett's esophagus include advanced age, male sex, white ethnicity, GERD, hiatal hernia, elevated body mass index, and a predominantly intra-abdominal distribution of body fat. Moderate consumption of wine and a diet high in fruits and vegetables may protect against the disorder.

Who Should Be Screened for Barrett's Esophagus?-Despite the considerable published data available on risk factors for Barrett's esophagus, few attempts have been made to apply this information systematically in the design of guidelines on who to screen for the condition. Furthermore, despite the dearth of studies showing clinical benefit resulting from endoscopic screening for Barrett's esophagus, the practice remains widespread among clinicians in the United States. ${ }^{70}$ Professional organizations are divided on whether to recommend endoscopic screening for Barrett's esophagus, however, with some suggesting that the practice may be appropriate ${ }^{71}$ and others not endorsing it routinely. ${ }^{72,73}$

Most recommendations on screening for Barrett's esophagus have focused on subjects with chronic GERD symptoms, because GERD was one of the first and strongest risk factors for Barrett's esophagus identified and because chronic esophageal inflammation due to GERD has been thought to contribute to esophageal carcinogenesis. Several cohort and case-control studies suggest that endoscopic screening and surveillance for Barrett's esophagus can have beneficial effects. ${ }^{74,75}$ Subjects who have esophageal adenocarcinoma discovered as the result of an endoscopic screening or surveillance program for Barrett's esophagus present with earlier-stage tumors, are less likely to have lymph node involvement, and have better short-term life expectancies than patients who present with symptoms of esophageal cancer such as dysphagia and weight loss. Cost-effectiveness analyses suggest that endoscopic screening may be cost-effective if certain predefined clinical parameters are met. ${ }^{76,77}$

Although these data may seem compelling, several conceptual and logistical difficulties diminish the utility of screening endoscopy as it is currently practiced in the United States. First and foremost, approximately $40 \%$ of subjects who have adenocarcinoma of the esophagus report no history of chronic GERD symptoms. ${ }^{78}$ Using GERD symptoms as an entrance criterion to endoscopic screening programs immediately excludes those subjects, decreasing by almost one-half our ability either to prevent the cancer or to detect it at an early, presymptomatic stage. Second, even among subjects with GERD symptoms, the risk of adenocarcinoma is very low in absolute terms. Studies show that up to $40 \%$ of the adult US population experience GERD symptoms on a monthly basis and $20 \%$ on a weekly basis. ${ }^{79}$ Although the incidence of adenocarcinoma of the esophagus has increased 6-fold in the past 3 decades,${ }^{80}$ fewer than 10,000 Americans develop esophageal adenocarcinoma each year, representing a minute fraction of the total number of individuals with GERD symptoms. Even among patients with Barrett's esophagus, cohort studies show that more than $90 \%$ never develop esophageal adenocarcinoma. ${ }^{81}$ Therefore, the vast majority of individuals who undergo endoscopic screening for Barrett's esophagus based on the presence of GERD symptoms will not benefit from the procedure.

There also are substantial problems with the execution of various facets of endoscopic screening and surveillance programs that diminish their effectiveness. These include difficulties in the endoscopic recognition of important lesions, ${ }^{82}$ the random nature of esophageal biopsy sampling that is subject to considerable sampling error, ${ }^{83}$ and disagreement among pathologists in the histologic interpretation of the esophageal biopsy specimens. ${ }^{84}$ Finally, endoscopic examinations are expensive, especially after factoring in costs not only for the endoscopy but also for the tissue acquisition and interpretation. 
No direct evidence substantiates the utility of endoscopic screening for Barrett's esophagus, and substantial confounding factors such as lead time and length bias compromise the validity of the observational studies, suggesting that the practice is beneficial. ${ }^{85}$ Therefore, inadequate evidence exists to endorse endoscopic screening for Barrett's esophagus based solely on the presence of GERD symptoms, and decisions on when to recommend endoscopic screening should continue to be individualized. It is incumbent on the practitioner to ensure that patients who elect to undergo endoscopic screening for Barrett's esophagus understand not only the putative advantages of the procedure but also the substantial shortcomings and possible negative effects, which include the expense and risks of the endoscopy and of the invasive procedures that might be recommended to treat lesions found by endoscopy as well as the potential adverse impact on quality of life (see the following text). Whether the development of new endoscopic technologies that are more sensitive, less expensive, and easier to perform or the availability of improved endoscopic treatments for Barrett's esophagus eventually will tip the scales in favor of screening is not yet known.

\section{What Is the Natural History of Dysplasia in Barrett's Esophagus?}

During the process of carcinogenesis in Barrett's esophagus, some of the genetic alterations that endow cells with growth advantages (eg, activation of oncogenes, inactivation of tumor suppressor genes) also cause morphologic changes in the tissue that the pathologist recognizes as dysplasia (also called intraepithelial neoplasia). Thus, dysplasia can be viewed as the histologic expression of genetic alterations that favor unregulated cell growth. ${ }^{86}$ Dysplasia can be categorized as low grade or high grade depending on the degree of histologic abnormalities. Pathologists can have difficulty distinguishing low-grade dysplasia in Barrett's esophagus from reactive changes caused by reflux esophagitis; consequently, interobserver agreement for the diagnosis of low-grade dysplasia may be poor.

Dysplasia in Barrett's esophagus sometimes causes no endoscopically apparent abnormalities, and dysplasia can be patchy both in its extent and severity. These factors contribute to the substantial problem of biopsy sampling error in identifying dysplasia. Endoscopists traditionally have used a 4-quadrant biopsy sampling system (which is essentially a random sampling technique) to find dysplasia in Barrett's esophagus, and it is clear that this system can miss areas of dysplasia and even cancer. In series of patients who underwent esophagectomies because endoscopic examination revealed high-grade dysplasia in Barrett's esophagus, for example, a number of studies have found that invasive cancer is present in $30 \%$ to $40 \%$ of the resected esophagi. ${ }^{87}$ However, a recent critical review of those studies suggests that $13 \%$ is a more accurate estimate of the frequency of invasive cancer in this situation, and when a careful endoscopic examination excludes all visible lesions, the frequency of finding invasive cancer at esophagectomy is only $3 \% .88$

A meta-analysis published in 2008 focused on the incidence of esophageal adenocarcinoma in patients with high-grade dysplasia in Barrett's esophagus. ${ }^{89}$ The literature search of MEDLINE and associated sources yielded 3843 citations, of which 196 were deemed potentially relevant; on complete review, however, only 4 articles met the inclusion criteria for the study (ie, study patients had histologically confirmed Barrett's esophagus with highgrade dysplasia, no prevalent cancer, and no ablative or surgical therapy). The crude incidence of esophageal adenocarcinoma among patients with high-grade dysplasia was 55.7 per 1000 person-years (5.6\% per year). Using different weighting algorithms, the incidence increased to 65.8 per 1000 person-years (6.6\% per year) with $95 \%$ CIs of 49.9 to 84.6 (Poisson) or 49.7 to 81.8 (binomial) per 1000 person-years of observation.

The incidence of cancer in patients who have low-grade dysplasia in Barrett's esophagus is especially poorly defined. Some studies have found a risk of cancer no greater than that for 
the entire population of patients with Barrett's esophagus, ${ }^{90-92}$ whereas others have observed considerably higher rates..$^{84,93}$ One reason for these disparities may be the poor interobserver correlation among pathologists in the diagnosis of low-grade dysplasia. ${ }^{94}$ This possibility is supported by the observation that, among patients whose diagnosis of lowgrade dysplasia is confirmed by 2 or more pathologists, the incidence of cancer is substantially higher than that for patients whose pathologists disagree on the diagnosis. ${ }^{84,93}$ The "extent" of low-grade dysplasia defined as the proportion of crypts that exhibit dysplastic changes has been suggested to improve the ability to discern which patients are at greater risk for development of cancer. ${ }^{95}$

Another unresolved issue is whether dysplasia can regress or whether the inability to demonstrate dysplasia on follow-up endoscopic examinations is merely the result of biopsy sampling error. In one of the largest multicenter longitudinal studies, $42 \%$ of patients initially diagnosed with low-grade dysplasia had no dysplasia found on subsequent endoscopic examinations and an additional $32 \%$ had low-grade dysplasia found only intermittently during their course of surveillance. ${ }^{92}$ In this study, the calculated incidence of esophageal adenocarcinoma among patients with low-grade dysplasia was $0.6 \%$ per year (95\% CI, 0-2\%), a rate of cancer development similar to that reported for the general population of patients with Barrett's esophagus. On the other hand, 3 patients in whom cancer developed did not have dysplasia diagnosed during prior endoscopic surveillance examinations. It is not clear whether those cancers developed de novo, without first manifesting dysplasia, or whether the preceding dysplasia merely was missed due to biopsy sampling error. Other reports also have described the apparent regression of dysplasia in the absence of ablation. ${ }^{22}$

\section{Does Endoscopic Surveillance Improve Survival for Patients With Barrett's Esophagus?}

Endoscopic surveillance has been proposed for patients with Barrett's esophagus with the unproved assumption that the practice will reduce deaths from esophageal adenocarcinoma and thereby prolong survival. Societal guidelines generally have recommended endoscopic surveillance for patients with Barrett's esophagus at intervals that vary with grade of dysplasia found in the metaplastic epithelium. Intervals of 3 to 5 years have been suggested for patients who have no dysplasia, 6 to 12 months for those found to have low-grade dysplasia, and every 3 months for patients with high-grade dysplasia who receive no invasive therapy. ${ }^{72}$

During endoscopic surveillance, the endoscopist attempts to identify esophageal neoplasia in an early, curable stage, usually in the form of dysplasia. To find dysplasia, endoscopists generally have relied on a systematic, 4-quadrant biopsy sampling technique designed with the intent of maximizing the chance for identifying an inconspicuous lesion that may be randomly distributed throughout the Barrett's epithelium. The "Seattle protocol" calls for obtaining such 4-quadrant biopsy specimens at intervals of every 1 to $2 \mathrm{~cm}$ throughout the columnar-lined esophagus. In addition, areas of mucosal irregularity (eg, nodules, masses, ulceration), which are especially likely to be associated with dysplasia, are sampled separately.

A prospective study showed a significant increase in the number of cases of high-grade dysplasia and invasive cancer detected after institution of a rigorous endoscopic surveillance protocol like the one described previously. ${ }^{96}$ In the community, however, surveillance often is not performed in this rigorous manner. A retrospective study of endoscopic and pathology reports from 15 hospitals in The Netherlands revealed that adherence to the Seattle protocol was good (79\%) for cases in which Barrett's metaplasia involved only up to $5 \mathrm{~cm}$ of the distal esophagus but diminished with increasing extent of metaplasia to the point that there was only $30 \%$ adherence among cases with metaplasia involving 10 to $15 \mathrm{~cm}$ of the 
esophagus. ${ }^{97}$ An American study using a large pathology database maintained by Caris Diagnostics identified 2245 patients who had esophageal biopsy specimens taken for evaluation of Barrett's esophagus and who had endoscopy reports that documented the extent of esophageal columnar lining. ${ }^{98}$ Overall, adherence to the Seattle protocol was found in only $51 \%$ of cases. As in the previous study, adherence to the protocol varied inversely with the extent of Barrett's metaplasia. In addition, failure to adhere to the protocol was associated with a significantly decreased rate of detecting dysplasia (summary odds ratio, $0.53 ; 95 \% \mathrm{CI}, 0.35-0.82$ ). These studies suggest that, although adherence to recommended surveillance procedures is associated with higher rates of detection of dysplasia, many practicing gastroenterologists do not adhere to those guidelines and adherence appears to be poorest for the population at highest risk for development of cancer (ie, patients with extensive Barrett's metaplasia).

Streitz et al studied 77 patients who they treated for esophageal adenocarcinoma to explore whether prior endoscopic surveillance was associated with better survival (Table 3) ${ }^{99}$ In 19 patients, the cancers were found during surveillance endoscopies performed because Barrett's esophagus had been discovered 8 to 120 months earlier (median, 24 months). The remaining 58 patients presented to the hospital with symptoms of esophageal cancer, and Barrett's esophagus was first diagnosed when their tumors were resected. Compared with the latter patients, the patients whose tumors were discovered during endoscopic surveillance had cancers in significantly lower stages and had a significantly better 5-year actuarial survival rate (62\% vs $20 \%)$. It should be noted that 9 patients in the surveillance group had esophagectomy performed for carcinoma in situ or high-grade dysplasia, although 2 of these had invasive carcinoma found in the resected specimen.

Peters et al reported the results of a similar study comparing outcomes for 17 patients who had esophagectomy performed for high-grade dysplasia or adenocarcinoma discovered during endoscopic surveillance with those for 35 patients who had esophagectomy for adenocarcinomas discovered outside a surveillance program. ${ }^{100}$ Although the endoscopic surveillance protocol was not standardized, all 17 patients had a diagnosis of Barrett's esophagus without cancer established at least 6 months before esophagectomy. Five of the 9 patients who underwent resection for high-grade dysplasia were found to have invasive cancer in the resected specimen. As in the previous study, the patients whose tumors were discovered during surveillance had cancers in significantly lower stages and longer survivals.

In another single-center experience, Van Sandick et al also compared outcomes for patients with adenocarcinoma of the esophagus or esophagogastric junction discovered in and outside endoscopic surveillance programs. ${ }^{75}$ The 16 patients in the surveillance group were known to have had Barrett's esophagus for a median duration of 42 months, and they had been under endoscopic surveillance for intervals ranging from 2 months to 2.5 years (median, 10 months). Five of those 16 patients had esophagectomy for high-grade dysplasia; 1 was found to have invasive cancer, 2 were found to have intramucosal carcinoma, and 2 had only high-grade dysplasia found in the resected esophagus. Compared with the 54 patients whose tumors were discovered outside a surveillance program, the pathologic stage of cancer was significantly lower for patients in the surveillance group, and their 2-year survival was significantly better $(85.9 \%$ vs $43.3 \% ; P=.0029)$. Surveillance was associated with significantly longer survival even when patients with a preoperative diagnosis of highgrade dysplasia (without cancer) were excluded from the analysis.

Fountoulakis et al studied a cohort of consecutive patients who underwent esophagectomy for high-grade dysplasia or adenocarcinoma in Barrett's esophagus, comparing the survival of those whose neoplasms were discovered in and outside a standardized endoscopic 
surveillance program. ${ }^{101}$ The surveillance group included 17 patients who had at least one endoscopy performed at least 6 months after their first diagnosis of Barrett's esophagus, whereas the no-surveillance group comprised 74 patients who first presented to the hospital with adenocarcinoma. Overall survival was significantly longer for patients in the surveillance group, with 1- and 3- year survival rates for the surveillance and nosurveillance groups of $88 \%$ versus $67 \%$ and $80 \%$ versus $31 \%$, respectively.

Using the Northern California Kaiser Permanente cancer registry, Corley et al studied outcomes for 589 patients with adenocarcinoma of the esophagus or gastric cardia diagnosed from 1990 to $1998 .{ }^{74}$ Among only 23 patients who were known to have had Barrett's esophagus for at least 6 months before the cancer was diagnosed, 15 had their tumors discovered during surveillance endoscopy, whereas 8 had their cancers detected during endoscopy performed because of cancer symptoms. As in the single-center observational studies discussed previously, the patients whose tumors were discovered during surveillance had cancers at significantly lower stages and had significantly better 2-year survival compared with the patients whose tumors were discovered because they were symptomatic (73.3\% vs $12.5 \% ; P=.02)$.

Cooper et al studied a cohort of 1633 patients in the Surveillance, Epidemiology and End Results (SEER) database who had adenocarcinoma of the esophagus or gastric cardia. ${ }^{102}$ Through linkage with Medicare claims data, the investigators were able to identify those who had endoscopy performed more than 1 year before the cancer was diagnosed. A record of prior endoscopy was found in only $9.7 \%$ of the patients, and only $3.7 \%$ had Barrett's esophagus identified at least 1 year before the diagnosis of cancer. However, a prior diagnosis of Barrett's esophagus was associated with a lower cancer stage and a higher probability of treatment by esophagectomy. The median survival for patients with esophageal adenocarcinoma who had a prior endoscopy was 7 months, compared with only 5 months for those who had no prior endoscopy $(P<.01)$. The association between prior endoscopy and prolonged survival remained significant even after adjusting for age at diagnosis, sex, race, and number of comorbidities using Cox proportional hazards modeling (relative hazards, 0.73 ; 95\% CI, 0.57-0.93).

A more recent analysis of the SEER-Medicare data conducted by Cooper et al included 2754 patients with a new diagnosis of esophageal adenocarcinoma. ${ }^{103}$ Having an endoscopy performed 3 years to 6 months before the diagnosis of cancer was associated with an improvement in median survival from 7 months (for patients with no prior endoscopy) to 11 months, yielding a significant reduction in the hazard ratio for death. Additional independent factors associated with improved survival included a prior diagnosis of Barrett's esophagus and receipt of therapy, including surgery, radiation, or chemotherapy. Of note, however, only $11.5 \%$ of the patients with cancer were found to have had a prior endoscopy, and Barrett's esophagus was identified in only $8.1 \%$ of patients before their diagnosis of cancer.

In a case-control study using the Veterans Affairs database, Kearney et al found that a group of 245 patients who had GERD and adenocarcinoma of the esophagus or gastric cardia were significantly less likely to have undergone endoscopy in the 1 to 8 years before the index date than 980 control subjects (matched by age, sex, and race) who had GERD without cancer (adjusted odds ratio, 0.66; 95\% CI, 0.45-0.96). ${ }^{104}$ Furthermore, a dose effect was noted whereby endoscopy performed 2 to 4 years before the index date was more protective against cancer death than endoscopy performed more than 4 years before that date.

Countering these positive results is a retrospective, controlled, cohort study by Rubenstein et al that used the Veterans Affairs national administrative databases to identify 155 subjects who had GERD associated with adenocarcinoma of the esophagus or esophagogastric 
junction. ${ }^{105}$ Although the 25 patients who had endoscopy performed 1 to 5 years before their diagnosis of cancer had tumors in a lower stage than the 130 patients who had no endoscopy during that same period, there was no significant difference in survival between the 2 groups (adjusted hazard ratio, $0.93 ; 95 \%$ CI, 0.58-1.50). Analysis of a subset of subjects for whom complete endoscopic and histopathologic data were available revealed that patients who had endoscopic surveillance performed according to guidelines proposed by the American College of Gastroenterology had better survival than those who did not. After adjustment for potential confounders, however, the improvement in survival did not achieve statistical significance. This study highlights the potential for lead- and length-time biases that can exaggerate the benefits of surveillance programs in observational studies.

In summary, the evidence to support endoscopic surveillance as a means to improve survival for patients who develop neoplasia in Barrett's esophagus relies on administrative data that have been examined retrospectively. The preponderance of this evidence suggests that endoscopic surveillance can reduce mortality from esophageal adenocarcinoma through the early detection of treatable cancers. However, such observational studies are prone to a number of biases, such as lead- and length-time biases, that could well exaggerate the benefits of surveillance programs. It remains unclear whether endoscopic surveillance is beneficial at all; consequently, it is not possible to make meaningful recommendations regarding the optimal intervals between endoscopic procedures or the optimal surveillance biopsy procedures.

\section{Can Biomarkers Be Used to Confirm the Histologic Diagnosis of Dysplasia? Can Biomarkers Be Used Instead of Dysplasia for Risk Stratification in Barrett's Esophagus?}

Can Biomarkers Be Used to Confirm the Histologic Diagnosis of Dysplasia?Presently, cancer risk stratification for patients with Barrett's esophagus is based primarily on the histologic finding of dysplasia. However, dysplasia is a very imperfect predictor of cancer risk for a number of reasons, including poor interobserver agreement among pathologists in distinguishing dysplasia from reactive epithelial changes (caused by reflux esophagitis) and in grading the severity of dysplastic change. ${ }^{84,106,107}$ Immunostaining for p53 has been proposed as an adjunct to the diagnosis of dysplasia, but the utility of this technique is limited by confounding factors such as high rates of false-positive staining and staining characteristics that vary with the type of p53 antibody used. ${ }^{108}$ Immunostaining for $\alpha$-methylacyl-CoA racemase (AMACR) and for a panel of biomarkers that includes $\beta$ catenin, cyclin D1, and p53 also has shown promise in preliminary studies for distinguishing dysplasia from reactive changes and for distinguishing among grades of dysplasia. ${ }^{109-111}$ In contrast to those promising reports, a study that attempted to correlate grades of dysplasia with messenger RNA expression levels for a panel of 10 genes believed to contribute to carcinogenesis in Barrett's esophagus found that the utility of the panel was severely limited by significant interpatient and intrapatient variations in gene expression levels. ${ }^{112}$ At this time, data supporting the use of biomarkers to confirm the histologic diagnosis of dysplasia must be considered preliminary, and biomarkers cannot yet be recommended for this purpose for routine clinical practice.

\section{Can Biomarkers Be Used Instead of Dysplasia for Risk Stratification in} Barrett's Esophagus?-A number of biomarkers other than the histologic finding of dysplasia have been proposed to predict the risk of neoplastic progression and, hence, the need for endoscopic surveillance or more invasive treatments in patients with Barrett's esophagus. In general, these putative biomarkers reflect DNA abnormalities, acquired during the process of carcinogenesis, that either endow the cells with growth advantages directly or favor the development of growth-promoting mutations. Most of the proposed biomarkers for Barrett's esophagus have been evaluated in cross-sectional studies only, and no biomarker 
yet has been validated in prospective, controlled clinical trials. However, some biomarkers have been evaluated in studies in which biopsy specimens of Barrett's metaplasia were collected in a prospective systematic fashion, but the biomarker analyses were performed retrospectively. Promising biomarkers that have been so evaluated include aneuploidy/ tetraploidy, $17 \mathrm{p}$ loss of heterozygosity ( $\mathrm{LOH})$, and several multiple biomarker panels.

Aneuploidy/tetraploidy: Genomic instability, which predisposes to the development of cancer-causing mutations, can be manifested by gains or losses in parts of chromosomes, a condition called aneuploidy. Aneuploidy can be detected in fresh frozen tissues by flow cytometry and in esophageal brushings or paraffin-embedded tissues by fluorescence in situ hybridization. Several reports suggest that flow cytometric evidence of aneuploidy and/or increased tetraploidy (specimens in which the fraction of cells with 4 sets of chromosomes exceeds 6\%) can predict neoplastic progression in Barrett's esophagus more accurately than the histologic grade of dysplasia. ${ }^{113-115}$

One study found that the 5-year cumulative incidence of cancer was $4 \%$ for patients with Barrett's esophagus who had biopsy specimens showing no dysplasia, indefinite dysplasia, or low-grade dysplasia (95\% CI, 1.6-9.0). ${ }^{113}$ If the flow cytometry in those same cases was normal, then the 5-year incidence of cancer was $0 \%$ (95\% CI, 0-4.7); if the flow cytometry showed aneuploidy or increased tetraploidy, then the 5-year incidence of cancer was $28 \%$ (95\% CI, 12.0-55.0). Thus, the results of flow cytometry provided more useful predictive information on cancer than the histologic finding of no to low-grade dysplasia. For patients with high-grade dysplasia, however, flow cytometry added little additional predictive information. These findings were confirmed in a subsequent study by the same investigators. ${ }^{114}$ The aforementioned studies suggest that aneuploidy or increased tetraploidy might be used to predict the risk of cancer in patients who have Barrett's esophagus with no dysplasia or only low-grade dysplasia. However, those studies detected aneuploidy/tetraploidy by flow cytometry performed on frozen tissue specimens.

Esophageal biopsy specimens rarely are frozen in clinical practice, and high-quality flow cytometry may not be widely available in clinical centers. These factors may have hindered the adoption of aneuploidy/tetraploidy as a clinical biomarker for neoplastic progression in Barrett's esophagus. In small studies, aneuploidy/tetraploidy detected by automated image cytometry and fluorescence in situ hybridization, techniques that might be more feasible for routine clinical practice, have been found to predict neoplastic progression in Barrett's esophagus. ${ }^{116,117}$ These preliminary findings require validation in high-quality prospective studies before the tests can be recommended for routine clinical application.

17p LOH: LOH for chromosome 17p, which harbors the $p 53$ gene, also has shown promise as a biomarker for neoplastic progression in Barrett's esophagus. In one study of patients with Barrett's esophagus whose biopsy specimens showed changes ranging from no dysplasia to high-grade dysplasia, the 3-year cumulative incidence of cancer was 38\% (95\% CI, 26.0-54.0) for those with $17 \mathrm{p} \mathrm{LOH} \mathrm{compared} \mathrm{with} \mathrm{only} 3.3 \%$ (95\% CI, 1.4-8.0) for those with 2 intact $17 \mathrm{p}$ alleles. ${ }^{118}$ In the subset of patients who had no dysplasia, indefinite dysplasia, or low-grade dysplasia, furthermore, $17 \mathrm{p} \mathrm{LOH}$ was a significant predictor of progression to high-grade dysplasia (RR, 3.6; 95\% CI, 1.3-10). Other studies by the same group of investigators confirm these findings. ${ }^{119}$

In the aforementioned studies, $17 \mathrm{p} \mathrm{LOH}$ was detected using a labor-intensive technique in which cells that were purified by flow cytometry were then subjected to whole-genome amplification followed by genotypic analyses for $\mathrm{LOH}$. More recently, cross-sectional studies have shown promising results using simpler fluorescence in situ hybridization analyses for $17 \mathrm{p} \mathrm{LOH}$ on biopsy and brush cytology specimens of Barrett's esophagus. ${ }^{120-123}$ However, one study that compared the techniques head to head found that 
fluorescence in situ hybridization had a lower sensitivity for detecting $17 \mathrm{p} \mathrm{LOH}$ than the flow cytometric approach. ${ }^{121}$

Biomarker panels: Numerous genetic abnormalities are acquired in variable sequences during the process of carcinogenesis in Barrett's esophagus. Therefore, it is not surprising that combinations of biomarkers in panels may be better at predicting the risk of neoplastic progression than individual biomarkers. For example, one study found that patients with Barrett's esophagus who had 3 biomarker abnormalities (aneuploidy/tetraploidy, 17p LOH, and 9p LOH) in their esophageal biopsy specimens had an 80\% incidence of cancer within 6 years, whereas those who had none of those abnormalities had an incidence of cancer of only $12 \%$ at 10 years. ${ }^{119}$ Compared with the latter group, the RR of cancer progression for patients with an abnormal biomarker panel was 38.7 (95\% CI, 10.8-138.5).

A gene methylation-based biomarker panel also has shown promise for predicting development of cancer in Barrett's esophagus. Promoter methylation is a process that can silence the expression of a number of genes, including cancer-preventing tumor suppressor genes. A study that evaluated methylation of a number of tumor suppressor genes in biopsy specimens of Barrett's esophagus found that methylation of p16, RUNX3, and HPP1 was associated with a significantly increased risk of progression to high-grade dysplasia or cancer. ${ }^{124}$ The investigators generated a mathematical model for predicting neoplastic progression in Barrett's esophagus that used the results of their methylation-based biomarker panel (that included the aforementioned tumor suppressor genes), the patient's age, and the extent of Barrett's metaplasia. When applied in a retrospective longitudinal fashion to a cohort of patients with Barrett's esophagus, this prediction model was able to identify patients destined to progress to high-grade dysplasia or cancer as early as 2 years before neoplasia was recognized. Another more recent study has confirmed the ability of a methylation-based biomarker panel to predict neoplastic progression in Barrett's esophagus. ${ }^{125}$

In summary, a number of individual biomarkers and panels of biomarkers have been proposed to predict the risk of neoplastic progression for patients with Barrett's esophagus. To date, however, none of these has been validated in prospective, controlled clinical trials. Available data on aneuploidy/tetraploidy and $17 \mathrm{p} \mathrm{LOH}$ suggest that these biomarkers are no better than the histologic finding of high-grade dysplasia for predicting progression of cancer in Barrett's esophagus. However, aneuploidy/tetraploidy, $17 \mathrm{p} \mathrm{LOH}$, and methylationbased biomarker panels may be superior to histology alone for risk stratifying those patients with Barrett's esophagus whose initial biopsy specimens show no dysplasia, indefinite dysplasia, or low-grade dysplasia. In certain circumstances, therefore, those biomarkers could be used in combination with histology for risk stratification. Current data suggest that the identification of aneuploidy by flow cytometry or the identification of $17 \mathrm{p} \mathrm{LOH}$ by the combination of flow cytometry, whole-genome amplification, and genotypic analysis are the best available biomarker techniques. Thus, the routine clinical use of biomarkers instead of dysplasia for risk stratification in Barrett's esophagus cannot be recommended at this time.

Nevertheless, it seems likely that the results of biomarker validation studies will be available in the near future and that biomarkers eventually will be used to determine which patients with Barrett's esophagus will benefit from endoscopic surveillance or ablative techniques.

\section{Should Chromoendoscopy or "Electronic Chromoendoscopy" Be Used to Enhance the Detection of Metaplasia and Dysplasia in Barrett's Esophagus?}

The Seattle biopsy protocol for endoscopic surveillance in Barrett's esophagus, which involves 4-quadrant biopsy sampling of every 1 to $2 \mathrm{~cm}$ of the columnar-lined esophagus, is time consuming, labor intensive, costly, and subject to considerable sampling error. A number of alternative endoscopic techniques have been proposed to enhance the detection of 
intestinal metaplasia and dysplasia in the esophagus. The ultimate goals for these advanced imaging techniques are to improve the endoscopic detection of curable neoplasia in Barrett's esophagus while reducing procedure time, expense, and sampling error.

Modern videoendoscopes use a charge-coupled device, which has a surface composed of photosensitive elements (pixels). In high-resolution endoscopes, the charge-coupled device has a large number of pixels $(600,000$ to $1,000,000)$ that provide detailed images of the mucosal surface. High-resolution endoscopy can be combined with magnification devices that enlarge the video image up to $150 \times .^{126-128}$ High-definition television systems, which can generate up to 1080 scanning lines on a screen, enable the projection of a high-quality image onto a large screen for ease of viewing. ${ }^{129}$ Compared with standard endoscopy, highresolution endoscopy appears to have higher sensitivity for detecting early neoplastic lesions in Barrett's esophagus. ${ }^{130,131}$ Indeed, it is not clear that the image enhancement techniques discussed in the following text add important information beyond that available by careful white light inspection of the esophagus using high-resolution endoscopy.

Chromoendoscopy involves the application of chemical agents (eg, Lugol's solution, methylene blue, indigo carmine, and acetic acid) that highlight various features of the esophageal mucosa in an attempt to improve the detection of abnormalities. ${ }^{132-140}$ Lugol's solution, which is taken up by esophageal squamous cells that contain glycogen, has been used to highlight the squamocolumnar junction and as an aid for identifying residual islands of Barrett's metaplasia (which are not stained by Lugol's solution) after endoscopic eradication therapy. ${ }^{141}$ Reports on the use of methylene blue, which is absorbed by intestinal-type epithelium that is not dysplastic, have described variable results. In a prospective, randomized, crossover trial that compared methylene blue-directed biopsy with standard 4-quadrant biopsy in 48 patients with Barrett's esophagus, the techniques were found to be similar for the detection of intestinal metaplasia and dysplasia, although the mean number of biopsies required to detect those conditions was significantly lower with methylene blue staining. ${ }^{135}$ In contrast, another randomized crossover study found that the 4-quadrant biopsy technique detected dysplasia significantly more often than the methylene blue-directed biopsy technique. ${ }^{136} \mathrm{~A}$ recent meta-analysis of 9 studies that included 450 total patients found that methylene blue staining and 4-quadrant biopsy techniques have similar rates for detecting intestinal metaplasia and dysplasia. ${ }^{140}$ Further decreasing enthusiasm for methylene blue staining is a study documenting that the technique causes DNA damage in Barrett's epithelium. ${ }^{142}$

Different mucosal pit patterns in columnar epithelia can be recognized by combining magnification endoscopy with the mucosal application of indigo carmine dye or acetic acid. Using acetic acid, Guelrud et al described 4 pit patterns in Barrett's epithelium (round, reticular, villous, and ridged) and found that the ridged and villous patterns were associated with intestinal metaplasia. ${ }^{141}$ Sharma et al studied 80 patients with Barrett's esophagus using indigo carmine and found that the ridged/villous mucosal pattern had high sensitivity (97\%) and reasonable specificity (76\%) for intestinal metaplasia. ${ }^{138}$ In addition, all of 6 patients with high-grade dysplasia were found to have a distorted or irregular glandular pattern. However, a prospective, randomized, crossover study of 28 patients found that indigo carmine chromoendoscopy did not increase the sensitivity for detecting early neoplasia in Barrett's esophagus beyond that of high-resolution white light endoscopy. ${ }^{131}$

"Electronic chromoendoscopy" can be achieved by techniques such as narrow band imaging (NBI), which uses spectral narrow-band optical filters to highlight vascular patterns on the mucosal surface, or by optimal band imaging and I-scan, which use a postprocessing technology to highlight contrast between squamous and columnar epithelia. ${ }^{143}$ In a preliminary study of 24 patients with high-grade dysplasia or early cancer in Barrett's 
esophagus, optimal band imaging was found to detect neoplasia with a sensitivity of $87 \%$ but with a positive predictive value of only $37 \% .{ }^{144}$ Some single-center studies have attempted to correlate the magnified NBI appearance of the mucosal glandular and vascular patterns with the presence of metaplasia and dysplasia. ${ }^{145,146}$ In one such prospective study of magnification NBI in 51 patients with Barrett's esophagus, a ridge/villous pattern predicted the presence of intestinal metaplasia with a sensitivity of $93.5 \%$ and a specificity of $86.7 \%$, whereas an irregular/distorted pattern predicted high-grade dysplasia with a sensitivity and specificity of $100 \%$ and $98.7 \%$, respectively. ${ }^{145}$ The magnified NBI images could not distinguish low-grade dysplasia from nondysplastic tissue, however. In another study, Kara et al showed that areas of high-grade dysplasia in Barrett's esophagus had at least one of 3 abnormal patterns by NBI: (1) an irregular/disrupted mucosal pattern, (2) an irregular vascular pattern, and (3) abnormal blood vessels. ${ }^{146} \mathrm{~A}$ randomized crossover trial that compared chromoendoscopy and NBI in 28 patients found no significant difference between the 2 techniques for the detection of high-grade dysplasia and early cancer (93\% vs $86 \%$ sensitivity), and neither technique was superior to high-resolution white light endoscopy in that regard. ${ }^{131}$ In another study, endoscopists were asked to identify dysplasia in still images of Barrett's epithelium taken during magnification endoscopy. The yield for identifying dysplasia in images taken with high-resolution white light endoscopy was $86 \%$, and prediction rates did not increase significantly with the addition of either chromoendoscopy or NBI. ${ }^{147}$

Two recent reports describe prospective studies that have compared the diagnostic yield of NBI (nonmagnified) with that of white light endoscopy. ${ }^{148,149}$ In one study of 65 patients who were known to have dysplasia in Barrett's esophagus, standard-resolution white light endoscopy was performed first, followed by NBI performed by another endoscopist who used NBI to detect and obtain biopsy specimens from areas suspicious for dysplasia. ${ }^{148}$ The lesions initially detected by standard endoscopy were then disclosed and biopsy was performed; finally, random 4-quadrant biopsy specimens were taken throughout the columnar-lined esophagus. NBI was found to identify more patients with dysplasia than standard-resolution white light endoscopy with random biopsy sampling (57\% vs $43 \% ; P<$. 001). NBI also found higher grades of dysplasia significantly more often than standard endoscopy (18\% higher grade with NBI than with standard vs $0 \%$ higher grade with standard than with NBI; $P<.001$ ). In a multicenter, randomized, crossover trial comparing NBI-targeted biopsies with high-resolution white light endoscopy and 4-quadrant biopsies in 123 patients with Barrett's esophagus, there were no significant differences between the 2 techniques in the frequency of detecting intestinal metaplasia (85\% for each technique) and dysplasia (71\% for NBI vs 55\% for white light endoscopy; $P=.15) .{ }^{149}$ However, significantly fewer biopsies were required to establish a diagnosis with NBI (3.6 vs 7.6 per procedure; $P<.0001)$.

Chromoendoscopy for Barrett's esophagus is time consuming, fraught with technical problems (eg, achieving uniform dye application), potentially hazardous (in the case of methylene blue), poorly standardized (regarding the interpretation of mucosal patterns), and subject to considerable interobserver variability. Studies comparing chromoendoscopy with standard-resolution endoscopy have had contradictory findings, and studies have not established any diagnostic advantage for chromoendoscopy beyond that which can be achieved by high-resolution white light endoscopy. Consequently, we do not advocate the routine use of chromoendoscopy in Barrett's esophagus. Electronic chromoendoscopy techniques such as NBI are less time consuming and technically easier to perform than chromoendoscopy but are still subject to problems of poor standardization and interobserver variability. The studies discussed previously suggest that NBI may be superior to standardresolution white light endoscopy for detecting esophageal metaplasia and dysplasia, but 
studies so far have not established a convincing advantage for NBI over high-resolution white light endoscopy.

We conclude that endoscopic surveillance is best performed with careful inspection of the columnar-lined esophagus using high-resolution white light endoscopy, with biopsy sampling of any lesions or suspicious areas so identified followed by 4-quadrant biopsy sampling of the Barrett's metaplasia. The use of NBI or similar electronic chromoendoscopy techniques cannot be advocated or discouraged at this time.

\section{Should Advanced Endoscopic Imaging Techniques Such as Autofluorescence Imaging, Confocal Laser Endomicroscopy, Diffuse Reflectance and Light Scattering Spectroscopy, and Optical Coherence Tomography Be Used to Enhance the Detection of Metaplasia and Dysplasia in Barrett's Esophagus?}

Cells contain endogenous fluorophores (eg, reduced nicotinamide adenine dinucleotide, porphyrins) that can absorb endoscopically delivered laser light and re-emit it as fluorescent light with distinctive spectroscopic characteristics. Autofluorescence imaging (AFI) exploits this phenomenon to highlight abnormal areas in Barrett's esophagus that can be targeted for biopsy sampling. ${ }^{150-152}$ AFI attempts to distinguish normal from neoplastic epithelia based on differences in their fluorescence spectra. An initial feasibility study found that AFI was a sensitive test that improved the rate of detecting high-grade dysplasia but with poor specificity that resulted in a positive predictive value of only $50 \% .{ }^{150}$

In a multicenter study of 84 patients, Curvers et al explored the diagnostic potential of "trimodal imaging" in which the esophagus is first inspected by high-resolution white light endoscopy, followed by AFI to rapidly highlight abnormal areas not detected by white light, followed by NBI to confirm the abnormality of areas highlighted by AFI. ${ }^{152}$ High-resolution white light endoscopy identified 16 patients with neoplasia, all of whom were also identified by AFI. In addition, AFI detected 11 patients with early neoplasia who were not identified by white light endoscopy. In total, AFI identified 102 abnormalities that were not seen by white light endoscopy, but with poor specificity resulting in a false-positive rate for neoplasia detection of $81 \%$. That false-positive rate was reduced to $26 \%$ by NBI examination. However, multi-modality imaging also missed neoplasia in 3 patients $(10 \%)$ for whom the condition was detected only by random 4-quadrant biopsies.

Confocal laser endomicroscopy involves examination of the gut mucosa using endoscopically delivered laser light, which is reflected back through a pinhole onto sensors that relay the signals to a computer, which translates the information into a cross-sectional microscopic image of the mucosa. ${ }^{153-158}$ Magnifications even beyond $1000 \times$ can be achieved with confocal laser endomicroscopy, allowing for real-time microscopic analysis of mucosal crypt architecture and capillaries. The use of this system with ultra-high magnifications $(450 \times$ and $1125 \times)$ to evaluate individual cellular and subcellular structures has been called "endocytoscopy." 159,160

Initial reports on confocal laser endomicroscopy from a single center, using a confocal laser endomicroscopy device integrated into the tip of a conventional videoendoscope, described excellent accuracy rates (85\%-94\%) for the detection of high-grade dysplasia in patients with Barrett's esophagus, most of whom had abnormalities seen by white light endoscopy. ${ }^{153,156}$ Another group used a probe-based confocal laser endomicroscopy device to study patients who had Barrett's esophagus without visible lesions and observed that the finding of fused glands identified advanced neoplasia with a sensitivity of $80 \%$ and with good interobserver agreement, as evidenced by a $\kappa$ value of $0.6 .{ }^{154} \mathrm{In}$ an ex vivo study of 166 biopsy specimens from 16 patients, the positive and negative predictive values of endocytoscopy for high-grade dysplasia/early cancer were found to be $44 \%$ and $83 \%$, 
respectively. ${ }^{160}$ At $1125 \times$ magnification, however, adequate assessment of endocytoscopy images was not possible in $22 \%$ of the target areas.

Both diffuse reflectance spectroscopy and light scattering spectroscopy have been used to study Barrett's esophagus. Diffuse reflectance spectroscopy analyzes light that has been scattered multiple times within the tissue before it is detected by the sensing device, whereas light scattering spectroscopy analyzes light that is scattered back to the sensing device after undergoing only a single scattering event. Algorithms have been developed to use the spectroscopic information so collected to distinguish nonneoplastic and neoplastic regions in Barrett's esophagus. ${ }^{161-163}$ Using the diffuse reflectance spectra collected from 16 patients, one diagnostic algorithm was able to distinguish high-grade dysplasia from low-grade dysplasia and nondysplastic tissue in Barrett's esophagus with a sensitivity of $86 \%$ and a specificity of $100 \% .{ }^{161}$ The sensitivity and specificity for separating any grade of dysplasia from no dysplasia were $79 \%$ and $88 \%$, respectively. Using light scattering spectroscopy data for 76 sites in 13 patients with Barrett's esophagus, Wallace et al found that a diagnostic algorithm based on nuclear enlargement had a sensitivity and specificity of $90 \%$ in distinguishing dysplastic from nondysplastic tissue. ${ }^{163}$

Optical coherence tomography uses near-infrared light to provide high-resolution crosssectional imaging of the esophageal mucosa. ${ }^{164}$ The technique is similar in principle to endosonography, but image formation in optical coherence tomography depends on variations in the reflectance of light (rather than ultrasonic waves) from different tissue layers. ${ }^{165-168}$ In an initial study of 121 patients with Barrett's esophagus, objective image criteria for Barrett's metaplasia (without dysplasia) were formulated on the basis of data obtained from 166 optical coherence tomography images that had corresponding biopsy specimens. ${ }^{166}$ Data from this training set were validated using 122 optical coherence tomography images that were obtained prospectively. The optical coherence tomography criteria so developed were found to have a sensitivity and specificity of $97 \%$ and $92 \%$, respectively, for the identification of Barrett's metaplasia.

The studies discussed previously describe some promising preliminary results for the advanced imaging techniques in the detection of esophageal metaplasia and dysplasia. To date, however, these advanced techniques have not been shown to provide additional clinical information (beyond that available by high-resolution white light endoscopy) sufficient to warrant their routine application in clinical practice.

\section{Should Proton Pump Inhibitors Be Used for Chemoprevention in Barrett's Esophagus? Should Nonsteroidal Anti-inflammatory Drugs Be Used for Chemoprevention in Barrett's Esophagus?}

Should Proton Pump Inhibitors Be Used for Chemoprevention in Barrett's Esophagus?-Chemoprevention involves the use of a pharmacologic agent to prevent the development of cancer. ${ }^{169}$ Whereas the process of carcinogenesis in Barrett's esophagus may span decades, studies on potential chemopreventive agents generally have evaluated the effects of those agents on surrogate markers for cancer development, such as dysplasia, rather than on the development of cancer itself. The validity of using such surrogate end points is not clear. Furthermore, although a number of agents have been proposed for chemoprevention in Barrett's esophagus, only one has been evaluated in prospective, randomized, controlled clinical trials. Based on available data, the most promising chemopreventive agents for this condition appear to be the proton pump inhibitors (PPIs) and the nonsteroidal anti-inflammatory drugs (NSAIDs).

The evidence to support potent acid suppression with PPIs as a chemopreventive strategy in Barrett's esophagus is largely indirect. In certain ex vivo and in vitro model systems, for 
example, acid has been shown to damage DNA and to induce proproliferative and antiapoptotic effects. ${ }^{170-173}$ By inference, therefore, gastric acid inhibition should be beneficial. A number of observational studies have found an inverse correlation between long-term use of PPIs and the incidence of dysplasia and adenocarcinoma in patients with Barrett's esophagus. ${ }^{174-177}$ Some prospective clinical studies have shown that PPI therapy is associated with a decrease in proliferation markers, a potentially cancer-protective effect, in biopsy specimens of Barrett's metaplasia. ${ }^{178-180}$ Unfortunately, prospective clinical studies have yet to prove that PPI therapy can prevent the development of dysplasia and its progression in Barrett's esophagus.

PPI therapy also has effects that, conceivably, might promote the development of cancer in Barrett's esophagus. For example, use of PPIs often is associated with an increase in the serum levels of gastrin, a hormone that has been shown to increase proliferation in Barrett's epithelium. Epidemiologic studies that have attempted to seek a cancer-promoting effect for PPIs have encountered the problem of confounding by indication, because long-term PPI therapy often is prescribed to treat GERD, which is a risk factor for esophageal adenocarcinoma. Thus, an association between PPIs and cancer may have nothing to do with the PPI, but rather may result from the underlying GERD for which the PPI is prescribed. Using the large general practitioners research database in the United Kingdom, for example, Garcia Rodriguez et al found that patients who were treated with acid suppression for an "esophageal indication" such as GERD had a significantly increased risk of developing esophageal adenocarcinoma (odds ratio, 5.42; 95\% CI, 3.13-9.39). ${ }^{181}$ In contrast, for patients who were treated with acid suppression for a "gastroduodenal indication" such as peptic ulcer disease, there was no significantly increased risk of adenocarcinoma (odds ratio, $1.74 ; 95 \%$ CI, 0.90-3.34). The lack of an association with cancer in patients taking PPIs for gastroduodenal disease suggests that the positive association in the patients with esophageal disease resulted from confounding by indication. In other words, it was likely the GERD, not the GERD treatment, that increased the incidence of cancer. Other studies on this issue also have not found a significant association between esophageal adenocarcinoma and the use of antisecretory agents per se. ${ }^{182,183}$

In summary, available circumstantial evidence supports the use of PPIs as a chemopreventive strategy in patients with Barrett's esophagus. Few would argue the need for PPIs to control GERD symptoms and to heal reflux esophagitis for these patients. However, insufficient data are available to support the practice of prescribing PPIs in dosages higher than those needed to eliminate the symptoms and endoscopic signs of GERD or, for patients with no such symptoms and signs, in dosages higher than those recommended as conventional for the treatment of GERD. Similarly, insufficient data are available to support the practice of using esophageal $\mathrm{pH}$ monitoring to titrate PPI dosing so as to normalize esophageal acid exposure for patients with Barrett's esophagus.

\section{Should Nonsteroidal Anti-Inflammatory Drugs Be Used for Chemoprevention in Barrett's Esophagus?-Multiple lines of evidence suggest that aspirin and other} NSAIDs protect against esophageal adenocarcinoma. There are data to suggest that NSAIDs exert their antitumor effects both through the inhibition of cyclooxygenase- 2 and through actions independent of cyclooxygenase inhibition. ${ }^{184,185}$ In vitro studies have shown that NSAIDs can decrease cellular proliferation, increase apoptosis, and interfere with angiogenesis, effects that would be expected to prevent cancer formation. ${ }^{186-189}$ In animal models of GERD, NSAIDs have been found to decrease the development of Barrett's esophagus and esophageal adenocarcinoma. ${ }^{190-192}$ In addition, decreased proliferation has been documented in biopsy specimens of Barrett's epithelium taken from patients who were treated with rofecoxib, a cyclooxygenase-2 selective NSAID. ${ }^{193}$ Irrespective of the 
underlying mechanism, ample experimental data suggest that NSAIDs may be effective chemopreventive agents for patients with Barrett's esophagus.

A number of epidemiologic studies also have supported the use of aspirin and other NSAIDs as chemopreventive agents in Barrett's esophagus. A meta-analysis of such studies by Corley et al found that the use of NSAIDs was associated with a 33\% reduction in the risk of developing esophageal adenocarcinoma (odds ratio, 0.67 ; 95\% CI, 0.51-0.87), and both aspirin and nonaspirin NSAIDs appeared to be equally effective in this regard. ${ }^{194}$ More recent studies on this issue have yielded contradictory results, however. A questionnairebased study that included approximately 300,000 members of AARP found no significant association between esophageal adenocarcinoma and the use of aspirin (1.00; 95\% CI, 0.731.37) or nonaspirin NSAIDs $(0.90 ; 95 \%$ CI, $0.69-1.17) .{ }^{195}$ In contrast, Vaughn et al prospectively studied a cohort of 350 patients with Barrett's esophagus followed up for 20,770 person-months and found that, compared with those who never used NSAIDs, current users of NSAIDs had a significantly decreased risk of esophageal adenocarcinoma (hazard ratio, 0.20; 95\% CI, 0.10-0.41). ${ }^{196}$ Finally, Heath et al randomized 100 patients who had either low- or high-grade dysplasia in Barrett's esophagus to receive either the cyclooxygenase- 2 selective NSAID celecoxib $200 \mathrm{mg}$ twice daily (49 patients) or placebo (51 patients). After 48 weeks of treatment, there was no significant difference between the 2 groups in the proportion of esophageal biopsy specimens showing dysplasia or cancer. ${ }^{197}$ However, this study had a number of limitations (eg, the use of dysplasia as the primary outcome, the use of a low dose of celecoxib) that may have affected the outcome.

Limited data suggest that biomarkers might have a role in identifying those patients with Barrett's esophagus who are most likely to benefit from chemopreventive therapies. For patients with Barrett's esophagus with DNA content abnormalities, 17p LOH, and/or 9p LOH in their esophageal biopsy specimens, for example, one study found that the use of NSAIDs was associated with a significant reduction in the risk of esophageal adenocarcinoma at 6 and 10 years of follow-up. ${ }^{119}$ In contrast, no beneficial effect of NSAIDs was seen in those patients whose biopsy specimens had none of those abnormalities.

NSAIDs clearly have substantial potential for toxicity, including serious gastrointestinal and cardiovascular side effects, and it is not clear whether the potential cancer-preventive effects warrant those risks. Even use of low-dose aspirin has been associated with serious bleeding complications. A meta-analysis of randomized controlled trials comparing low-dose aspirin (75-325 mg) and placebo for cardiovascular prophylaxis found that the absolute annual increase in risk attributable to aspirin was only $0.13 \%$ (95\% CI, 0.08-0.20) for major bleeding, $0.12 \%$ (95\% CI, 0.07-0.19) for major gastrointestinal bleeding, and $0.03 \%$ (95\% CI, 0.01-0.08) for intracranial bleeding. ${ }^{198}$ Thus, the overall risk of using low-dose aspirin is small. Moreover, patients included in that meta-analysis were not receiving concomitant PPI therapy, which has been shown to reduce the risk of gastrointestinal bleeding with lowdose aspirin by a factor of 2 to $9 .{ }^{199,200}$ Typically, the diagnosis of Barrett's esophagus is made in men older than 50 years of age and, as discussed previously, those patients may be at increased risk for cardiovascular disease. Low-dose aspirin has been shown to be beneficial for primary cardiovascular events in men older than 50 years of age who are at risk for developing coronary artery disease. ${ }^{201,202}$ Thus, low-dose aspirin has the potential to prevent cardiovascular events as well as esophageal cancer.

In summary, most available reports suggest that aspirin and other NSAIDs protect against the development of cancer in Barrett's esophagus, but definitive studies are lacking. Presently, we believe that it is appropriate to consider the prescription of low-dose aspirin for patients with Barrett's esophagus who also have risk factors for cardiovascular disease. 
Whereas patients will already be taking a PPI, the risks of aspirin causing serious gastrointestinal toxicity in average-risk individuals should be minimal. A large, prospective, randomized clinical trial in the United Kingdom is investigating the chemopreventive effects of PPIs alone and in combination with aspirin (AspECT), and the results of that study are eagerly awaited. ${ }^{203}$

\section{Should Antireflux Surgery Be Advised to Prevent Cancer in Barrett's Esophagus?}

For many patients with Barrett's esophagus, PPI therapy eliminates GERD symptoms, but esophageal acid exposure remains abnormal nevertheless. ${ }^{204-206}$ In one study of 48 patients with Barrett's esophagus who had been rendered asymptomatic by PPI treatment, for example, $50 \%$ had persistently abnormal acid exposure documented by esophageal $\mathrm{pH}$ monitoring. ${ }^{206}$ Even if PPIs normalize acid reflux, the reflux of nonacidic gastric material persists and, conceivably, bile and other noxious agents in that refluxed material might contribute to carcinogenesis in Barrett's esophagus. As noted previously, furthermore, PPIs themselves have effects that, in theory, might promote development of cancer (eg, elevated serum gastrin levels, bacterial colonization of the stomach). For all these reasons, it has been proposed that fundoplication, which is designed to eliminate gastroesophageal reflux, might be more effective than antisecretory therapy for preventing cancer in Barrett's esophagus. ${ }^{207}$

A number of observational studies have described fewer cases of dysplasia and cancer developing in patients with Barrett's esophagus who had antireflux surgery than in those who had received medical treatment. ${ }^{208-210}$ Those studies generally have been small and subject to numerous biases that might inflate the benefits of surgical therapy. Higher-quality studies have not found that antireflux surgery is superior to medical therapy for prevention of cancer in Barrett's esophagus.

During 10 to 13 years of follow-up for patients (many of whom had Barrett's esophagus) who had participated in a randomized trial of medical and surgical therapies for GERD, 4 of 165 patients $(2.4 \%)$ in the medical group and 1 of $82(1.2 \%)$ in the surgical group developed an esophageal adenocarcinoma. ${ }^{211}$ The difference between the treatment groups in the incidence of this malignancy was not statistically significant but, with such a low observed rate of cancer development, the study did not have sufficient statistical power to detect a small cancer-protective effect for fundoplication.

Two studies using large patient databases ${ }^{212,213}$ and 3 meta-analyses $22,214,215$ also have found no significant cancer-preventive effect for antireflux surgery. In one meta-analysis, Chang et al initially found that the incidence of esophageal adenocarcinoma in Barrett's esophagus was significantly lower in surgically treated patients (2.8 [95\% CI, 1.2-5.3] per 1000 patient-years) than in medically treated patients (6.3 [95\% CI, 3.6-10.1]; $P=.034) .{ }^{22}$ However, the investigators found that there was significant heterogeneity in the cancer incidence rates reported in case series compared with the higher-quality controlled studies $(P=.014)$. In the controlled studies, there were no significant differences in cancer incidence rates between surgically and medically treated patients (4.8 [1.7-11.1] vs 6.5 [2.613.8 ] per 1000 patient-years, respectively; $P=.32$ ). The authors concluded that evidence suggesting that surgery reduced the risk of cancer in Barrett's esophagus was driven largely by uncontrolled studies.

In summary, there is no convincing evidence that antireflux surgery is more effective than medical therapy for prevention of cancer in Barrett's esophagus. We conclude that antireflux surgery should not be advised with the rationale that the procedure will prevent esophageal cancer. 
What Is the Role for EMR in Barrett's Esophagus? Should Endoscopic Eradication Be Used to Treat Patients Who Have Barrett's Esophagus Without Dysplasia? Should Endoscopic Eradication Be Used to Treat Patients Who Have Barrett's Esophagus With Low-Grade Dysplasia? Should Endoscopic Eradication Be Used to Treat Patients Who Have Barrett's Esophagus With High-Grade Dysplasia or Intramucosal Carcinoma?

What Is the Role for EMR in Barrett's Esophagus?-In EMR, a diathermic snare or endoscopic knife is used to remove Barrett's metaplasia down to the submucosa, providing large tissue specimens that can be used to assess the depth of any neoplastic involvement and the adequacy of the resection. Thus, EMR has potential value as both a diagnostic/ staging procedure and as a therapeutic procedure for removing Barrett's epithelium with and without neoplasia.

In surgical series of patients who have undergone esophagectomy for the treatment of highgrade dysplasia or intramucosal adenocarcinoma in Barrett's esophagus, lymph node metastases have been described in $0 \%$ to $7 \%{ }^{216-220}$ For patients whose tumors extend into the submucosa, however, the frequency of lymph node metastases often exceeds $20 \% .{ }^{216,217,220}$ For this reason, endoscopic therapy generally is not considered definitive for patients with neoplasms that involve the submucosa. When considering endoscopic eradication therapy for neoplasia in Barrett's esophagus, therefore, accurate T staging is essential. Although endoscopic ultrasonography (EUS) is considered the most accurate imaging modality for the $\mathrm{T}$ staging of gastrointestinal cancers, standard EUS accurately predicts the depth of invasion for early esophageal cancers in only $50 \%$ to $60 \%$ of cases. ${ }^{221}$ Even high-frequency probe EUS is inadequate in this situation, as evidenced by one study of 9 patients who underwent esophagectomy for early neoplasia in Barrett's esophagus in whom preoperative T staging by high-frequency probe EUS was found to be accurate in only 4 cases. ${ }^{222}$

In a study of 40 patients with neoplasia in Barrett's esophagus who had EMR performed after endoscopic biopsy and EUS, histologic review of the EMR specimen revealed intramucosal carcinoma in $24 \%$ of patients with an EUS/biopsy diagnosis of high-grade dysplasia and invasive cancer in $40 \%$ of patients with an EUS/biopsy diagnosis of intramucosal carcinoma. ${ }^{223}$ In a study in which preoperative EMR findings were compared with subsequent histologic examination of esophagectomy specimens for 25 patients with high-grade dysplasia or adenocarcinoma in Barrett's esophagus, there was perfect agreement in T staging by EMR and esophagectomy. ${ }^{224}$ These studies show that EMR can be considered a valuable diagnostic/staging procedure for identifying submucosal invasion that might not be apparent by less invasive techniques such as mucosal biopsy and EUS.

In addition to its role in staging neoplasms in Barrett's esophagus, EMR also has been used to eradicate Barrett's epithelium, high-grade dysplasia, and early Barrett's cancers. Cohort studies have found that EMR can achieve complete eradication of Barrett's epithelium in $75 \%$ to $100 \%$ of cases and complete eradication of dysplasia in $86 \%$ to $100 \%$ of cases. $^{225-232}$ At this time, there are no published randomized trials comparing EMR with other endoscopic therapies for the eradication of Barrett's epithelium.

\section{Should Endoscopic Eradication Be Used to Treat Patients Who Have Barrett's Esophagus Without Dysplasia?-Endoscopic eradication therapy for Barrett's esophagus includes EMR and/or the endoscopic ablative techniques, which use thermal, photochemical, or radiofrequency energy to destroy the Barrett's epithelium without providing a tissue specimen. Following ablation or EMR, patients are prescribed antireflux therapy (usually PPIs) so that the eradicated esophageal mucosa heals with the growth of new squamous epithelium (also called neo-squamous epithelium). Endoscopic ablation for Barrett's esophagus was first described in 1992, and early feasibility studies were conducted}


in patients with nondysplastic Barrett's esophagus. Presently, endoscopic therapies are being used primarily to treat patients with dysplasia and early adenocarcinoma in Barrett's esophagus.

The earliest studies of endoscopic ablative therapy used lasers to destroy nondysplastic Barrett's epithelium. Since then, the techniques that have been studied most extensively for the eradication of Barrett's esophagus without dysplasia include multi-polar electrocoagulation (MPEC), argon plasma coagulation (APC), and radiofrequency ablation (RFA). ${ }^{233-243}$ Most reports of such studies describe case series, and there is considerable heterogeneity among those studies regarding the primary end points (eg, complete eradication, partial eradication, percentage regression of Barrett's metaplasia), the duration of follow-up, and the postablation surveillance protocols.

For MPEC, several prospective case series have described the complete eradication of nondysplastic Barrett's epithelium in $65 \%$ to $100 \%$ of cases. In a study involving only 14 patients, Montes et al reported a complete eradication rate of $100 \%$ during a mean follow-up of 21.6 months. ${ }^{233}$ In contrast, another study of 58 patients followed up for 6 months found a complete eradication rate of only $78 \% .^{234}$

For APC, the complete eradication of nondysplastic Barrett's esophagus has been described in $36 \%$ to $100 \%$ of cases, with recurrences found in up to $66 \%$ of the treated patients. In a cohort of 70 patients treated with APC and followed up for a median of 51 months, Madisch et al reported a complete eradication rate of $98 \%$, with a recurrence rate of $12 \% .{ }^{237} \mathrm{In}$ contrast, another study of 25 patients treated with APC noted an initial complete eradication rate of only $84 \%$ and found a recurrence rate of $66 \%$ during a median follow-up period of 30 months. ${ }^{238}$ Manner et al used high-power $(90 \mathrm{~W})$ APC to treat 51 patients who had Barrett's esophagus without dysplasia. ${ }^{243}$ Nine of the 51 patients (18\%) experienced transient side effects, including chest pain, fever, and odynophagia. Five patients (10\%) had a major complication, including hemorrhage (2 patients), esophageal stricture (2 patients), and esophageal perforation (1 patient). During a mean follow-up of 14 months, complete eradication of Barrett's epithelium was achieved in 37 of the 48 patients (77\%) who had follow-up examinations.

Bright et al randomized 40 patients with Barrett's esophagus who had undergone antireflux surgery to receive either APC or endoscopic surveillance without ablative therapy. ${ }^{240}$ During a median follow-up period of 68 months, complete eradication of Barrett's epithelium was achieved in $40 \%$ of patients treated with APC compared with $20 \%$ in the surveillance group. One patient treated with APC was found to have progression to lowgrade dysplasia, whereas 2 patients in the surveillance group developed low-grade dysplasia and another 2 progressed to high-grade dysplasia during the same period of follow-up.

Two randomized trials have compared MPEC and APC for the treatment of Barrett's esophagus without dysplasia. In a study of 35 such patients followed up for 2 years, Sharma et al found no significant differences in the percentage of complete eradication for 16 patients treated with MPEC (75\% complete eradication) compared with 19 patients treated with APC (63\% complete eradication; $P=.49) .{ }^{235}$ Both techniques required multiple treatment sessions ( 4 for MPEC vs 3 for APC; not significant), and no factors were identified that could be used to predict complete eradication. The other randomized trial involved 52 patients and also found no significant differences between the treatment groups in the percentage of complete eradication ( $81 \%$ for MPEC vs $65 \%$ for APC; $P=.21$ ). ${ }^{236}$

In another comparative trial, 68 patients who had Barrett's esophagus without dysplasia were randomized to receive treatment with either APC or photodynamic therapy (PDT) using 5aminolevulinic acid as the photosensitizer. During a median follow-up period of 12 months, 
complete eradication was noted in $97 \%$ of patients in the APC group compared with only $50 \%$ of patients who received PDT $(P<.0001) .{ }^{239}$

RFA therapy uses a balloon-based circumferential array of closely spaced electrodes to deliver radiofrequency energy to the esophageal mucosa. This system was designed with the intent of inflicting a uniform circumferential thermal injury with depth that is controlled by a generator, which can vary the power, density, and duration of the energy applied. In one study of 70 patients who had Barrett's esophagus without dysplasia, RFA resulted in apparent complete eradication of Barrett's epithelium in $69 \%$ of patients at 12 months. ${ }^{241}$ Noting the problem of frequent incomplete eradication, the RFA manufacturer introduced a smaller, endoscope-mounted, radiofrequency catheter ablation device to be used for the focal ablation of metaplasia that remains behind after treatment with the circumferential system. In a 30-month follow-up study of the same cohort described in the aforementioned report, use of the focal ablative device resulted in the complete eradication of Barrett's epithelium in $97 \%$ of the patients. ${ }^{242}$

The reports described previously establish that endoscopic ablative therapies can eradicate nondysplastic Barrett's epithelium in the short-term for the majority of patients. However, those reports do not establish the benefit of that eradication. Some reports describe a high rate of recurrent metaplasia, and it is not clear that any ablative procedure provides longterm protection from esophageal cancer. A recent cost-utility analysis suggests that ablation of nondysplastic Barrett's epithelium could be a preferred management strategy if the procedure eliminates the need for long-term endoscopic surveillance, with its attendant risks and expense. ${ }^{244}$ However, in the absence of long-term studies showing efficacy, it is not clear that surveillance should be discontinued after ablation therapy. Consequently, it is not clear that the potential benefit of ablation in reducing the small risk of cancer for patients who have Barrett's esophagus without dysplasia warrants the risks and substantial expense of the ablative procedures.

\section{Should Endoscopic Eradication Be Used to Treat Patients Who Have Barrett's Esophagus With Low-Grade Dysplasia?-Few studies have focused exclusively on} the efficacy of endoscopic eradication for patients with low-grade dysplasia in Barrett's esophagus. Rather, such patients commonly have been included as a subgroup in eradication trials that have involved primarily patients without dysplasia or patients with high-grade dysplasia, a feature that can confound the interpretation of study results. Overall, eradication rates for low-grade dysplasia have ranged from $35 \%$ to $100 \%$, with a similar range for recurrence rates.

One study that used APC to ablate dysplastic Barrett's epithelium found complete eradication of low-grade dysplasia in all of 19 patients followed up for a median of 12 months. ${ }^{245}$ Using PDT with 5-aminolevulinic acid, Ackroyd et al completely eradicated low-grade dysplasia in all of 40 patients during a mean follow-up of 53 months. ${ }^{246}$ Another study using PDT, this time with sodium porfimer $(n=14)$, found complete eradication of low-grade dysplasia in 13 of 14 patients $(93 \%)$ followed up for a mean of 50.7 months. ${ }^{247} \mathrm{~A}$ randomized trial that compared the efficacies of APC and PDT (with porfimer sodium) for treating low-grade dysplasia found substantially lower rates of complete eradication (62\% with APC vs. 77\% with PDT), with no significant difference between the 2 treatment groups in the frequency of complete eradication. ${ }^{248}$ In a recent single-center study that used RFA to treat 39 patients with low-grade dysplasia, complete eradication of dysplasia was achieved in $95 \%$, and $87 \%$ had complete eradication of Barrett's metaplasia during a median followup of 24 months. ${ }^{249}$ 
Recently, Shaheen et al reported the results of a multicenter, prospective, randomized, shamcontrolled trial on endoscopic eradication that included 64 patients with low-grade dysplasia in Barrett's esophagus who were randomized to receive either RFA (42 patients) or a sham procedure (22 patients). ${ }^{250}$ At 12 months, complete eradication of low-grade dysplasia was achieved in $90 \%$ of patients in the RFA group compared with $23 \%$ in the sham group $(P<$. 001). Complete eradication of Barrett's metaplasia was achieved in $81 \%$ and $4 \%$ of the RFA and sham groups, respectively $(P<.001)$. During the trial period, however, there was no significant difference between the RFA and sham treatment groups in the percentage of patients who had progression from low-grade to high-grade dysplasia (5\% in the RFA group and $14 \%$ in the sham group; $P=.33$ ), and no patient with low-grade dysplasia in either group progressed to cancer.

The conclusions that can be drawn from studies on endoscopic eradication therapy for lowgrade dysplasia are similar to those for the eradication of nondysplastic Barrett's esophagus discussed previously. Available reports establish that ablative therapies can eradicate lowgrade dysplasia in the short-term for the majority of patients, but the reports do not establish the benefit of that eradication. Difficulties in verifying a diagnosis of low-grade dysplasia (see the previous text) and uncertainty regarding its natural history further confound the situation. In the absence of long-term studies showing efficacy, it is not clear that the potential benefit of ablation in reducing cancer risk for patients who have Barrett's esophagus with low-grade dysplasia warrants the risks and substantial expense of the ablative procedures.

\section{Should Endoscopic Eradication Be Used to Treat Patients Who Have Barrett's Esophagus With High-Grade Dysplasia or Intramucosal Carcinoma?-In a} recent study of 39 patients with neoplasia in Barrett's esophagus (25 high-grade dysplasia, 14 early cancers), sequential EMR (mean of 3 sessions) resulted in complete eradication of neoplasia in all patients and complete eradication of Barrett's epithelium in 89\%, with no recurrences observed during a median follow-up of 11 months. ${ }^{251}$ The largest reported experience with EMR as the primary technique to eradicate high-grade dysplasia and early cancer in Barrett's esophagus involved 349 patients followed up for a mean of 63.6 months. ${ }^{232}$ The early complete eradication rate for neoplasia was $97 \%$, but metachronous neoplasms subsequently developed in $21.5 \%$ of patients; $85 \%$ of those patients received further endoscopic eradication therapy and achieved a second complete remission. Risk factors for metachronous neoplasms identified in this study included piecemeal resection of the lesion (RR, 2.4; 95\% CI, 1.13-4.89), long-segment Barrett's esophagus (RR, 1.9; 95\% CI, 1.06-3.3), no use of mucosal ablative therapies after EMR (RR, 2.5; 95\% CI, 1.523.85 ), time until complete remission achieved greater than 10 months (RR, 0.3; 95\% CI, 0.12-0.75), and multifocal neoplasia (RR, 2.1; 95\% CI, 1.16-3.9).

For the treatment of high-grade dysplasia in Barrett's esophagus, PDT was the first endoscopic ablative modality to be evaluated in a randomized controlled trial. In that trial, 208 patients with high-grade dysplasia were randomized either to the control group, which received treatment with omeprazole alone, or to the group that received treatment with PDT (using porfimer sodium as the sensitizing agent) plus omeprazole. In the initial report of this study, when the duration of follow-up was 2 years, the primary goal of complete eradication of high-grade dysplasia was achieved in 77\% of patients in the PDT group compared with $39 \%$ of patients in the control group $(P<.0001) .{ }^{252}$ In a subsequent follow-up study of those patients at 5 years, intention-to-treat analyses showed that PDT was significantly more effective than omeprazole alone for eradicating high-grade dysplasia (77\% [106/138] vs $39 \%$ [27/70]; $P<.0001)$ and that PDT-treated patients were less likely to progress to cancer (15\% vs $29 \% ; P=.027$ ), although the trial was not designed specifically to test this outcome. ${ }^{253}$ In addition to this randomized controlled trial, a number of small uncontrolled 
studies of PDT (using 5-aminolevulinic acid as the sensitizing agent) for the treatment of high-grade dysplasia or early cancer in Barrett's esophagus have found complete eradication rates ranging from $77 \%$ to $100 \% .254,255$

Reports of uncontrolled studies have described promising results for RFA for patients with high-grade dysplasia in Barrett's esophagus. In a single-center study in which 24 patients with high-grade dysplasia were treated with RFA and followed up for up to 24 months, complete eradication of dysplasia and intestinal metaplasia was found in $79 \%$ and $67 \%$ of patients, respectively. ${ }^{249}$ A multicenter registry of 142 patients with high-grade dysplasia treated with RFA therapy described complete eradication of dysplasia and intestinal metaplasia in $90 \%$ and $54 \%$ of patients, respectively. ${ }^{256}$

The previously mentioned prospective, sham-controlled trial of RFA by Shaheen et al included 63 patients with high-grade dysplasia in Barrett's esophagus who were randomized to receive either RFA (42 patients) or a sham procedure (21 patients). ${ }^{250}$ At 12 months, after an average of 3.5 endoscopic sessions, complete eradication of high-grade dysplasia was achieved in $81 \%$ of patients in the RFA group compared with $19 \%$ in the sham group $(P<$. 01). Complete eradication of Barrett's metaplasia was achieved in $74 \%$ and $0 \%$ of the RFA and sham groups, respectively $(P<.001)$. Furthermore, 4 patients in the sham group progressed to cancer compared with only 1 in the RFA group $(P=.04)$.

Reports of small studies have described the use of cryotherapy and APC to eradicate highgrade dysplasia and early cancer in Barrett's esophagus. ${ }^{257,258}$ In a prospective trial that used CryoSpray in 31 patients ( 26 with high-grade dysplasia, 5 with early cancer), complete eradication of neoplasia and intestinal metaplasia was achieved at 12 months in $23 \%$ and $1 \%$ of patients, respectively. ${ }^{258}$ Although these results may seem unimpressive, it should be noted that $27 \%$ of the patients had previous unsuccessful attempts at endoscopic eradication with other modalities. Attwood et al used APC in 29 patients with high-grade dysplasia and reported complete eradication of dysplasia and intestinal metaplasia in $86 \%$ and $76 \%$ of patients, respectively. ${ }^{259}$ However, 4 patients developed cancer during a 37-month followup period.

Most of the studies discussed previously on endoscopic ablation of neoplasia in Barrett's esophagus have evaluated the results of a single ablative technique performed without EMR. However, an emerging concept in the endoscopic management of neoplasia in Barrett's esophagus is that endoscopic eradication may be best effected by first removing visible abnormalities with EMR, which provides invaluable staging information as well as therapy, followed by the ablation of all remaining Barrett's metaplasia. In the aforementioned study by Pech et al on endoscopic eradication therapy for patients with high-grade dysplasia or intramucosal carcinoma in Barrett's esophagus, metachronous neoplasms were detected during follow-up in $30 \%$ of 137 patients treated with EMR alone, whereas metachronous neoplasms were found in only $17 \%$ of 200 patients who were treated with EMR followed by ablation with APC or PDT. ${ }^{232}$ In a recent multicenter European trial, 23 patients with neoplasia in Barrett's esophagus ( 7 with high-grade dysplasia, 16 with early cancer) had EMR followed by RFA. ${ }^{260}$ At a median follow-up of 22 months, complete eradication of neoplasia and intestinal metaplasia was achieved in $95 \%$ and $88 \%$ of patients, respectively.

Major complications of endoscopic eradication therapy for Barrett's esophagus include esophageal stricture formation, bleeding, and perforation. Minor complications include transient chest pain, fever, and odynophagia. After PDT and RFA, esophageal stricture development has been reported in up to $36 \%$ and $6 \%$ of patients, respectively. ${ }^{250,258}$ After EMR, esophageal stricture formation has been observed primarily in patients treated with circumferential resections that were aimed at eliminating all Barrett's epithelium.227,229 
Rates of bleeding with the various modalities have varied from 0 to $10 \%$, and perforations are uncommon.

Although a number of studies describe complete elimination of all Barrett's epithelium after endoscopic eradication therapy, this claim is suspect because it is based on endoscopic appearance and on random biopsy sampling techniques. These practices do not eliminate the possibility that the eradication procedure caused squamous epithelium to grow over foci of Barrett's epithelium (so-called "buried" metaplasia), which may retain malignant potential. Buried metaplasia easily can be missed as the result of biopsy sampling error, and superficial biopsy specimens of squamous epithelium that do not provide at least some lamina propria are not informative for buried metaplasia. Indeed, without resecting the esophagus and examining its full thickness histologically, it is virtually impossible to exclude the presence of buried metaplasia. A recent systematic review found that buried metaplasia was associated with dysplasia or cancer in the buried glands in 0 to $30 \%$ of patients in studies on endoscopic eradication therapy. ${ }^{261}$

One recent study suggests that the risk of buried metaplasia following eradication therapy may be exaggerated, because buried metaplasia can be found with similar frequency in patients who are treated with PPIs alone (without endoscopic ablation). Bronner et al examined biopsy specimens of esophageal squamous epithelium taken during the previously mentioned randomized trial of PDT for patients with high-grade dysplasia in Barrett's esophagus. ${ }^{262}$ After reviewing 33,658 esophageal biopsy specimens, the investigators found no significant difference in the frequency of squamous overgrowth (buried metaplasia) between the group treated with PDT (39 of 132 patients; 30\%) and the group that received omeprazole alone ( 22 of 67 patients; $33 \% ; P>.05$ ). Furthermore, the highest grade of neoplasia per endoscopy was not found exclusively in the buried metaplasia in any patient. Apparently, squamous epithelium frequently grows over metaplastic glands in patients who are treated with PPIs, perhaps as a consequence of the extensive esophageal biopsy procedures used during endoscopic surveillance.

Whether or not the risk of buried metaplasia after ablation is exaggerated, it is clear that cancer can develop in some patients who are treated with endoscopic eradication therapy. A recent systematic review and meta-analysis found 43 reported cases of esophageal cancer that occurred in patients who had undergone endoscopic ablation for Barrett's esophagus without dysplasia (4 of 1457 cases), low-grade dysplasia ( 2 of 239 cases), or high-grade dysplasia (37 of 611 cases). ${ }^{263}$ Those data were used to calculate weighted-average incidence rates for cancer development after endoscopic ablation therapy as follows: 1.63 cancers per 1000 patient-years (95\% CI, 0.07-3.34) for Barrett's esophagus without dysplasia, 1.58 cancers per 1000 patient-years (95\% CI, 0.66-3.84) for low-grade dysplasia, and 16.76 cancers per 1000 patient-years (95\% CI, 10.6-22.9) for high-grade dysplasia.

In summary, large, prospective, randomized trials have established that endoscopic ablation therapy with PDT and RFA is superior to treatment with PPIs alone for preventing the progression from high-grade dysplasia to cancer in Barrett's esophagus. Compared with PDT with porfimer sodium, RFA appears to have a better safety profile and is easier to administer. Large, nonrandomized, and uncontrolled cohort studies have shown excellent long-term survival rates for carefully selected patients with high-grade dysplasia and early cancer who are treated with EMR. Recurrent or metachronous cancers occur frequently in those patients, however, especially if the residual Barrett's epithelium is not ablated. Nevertheless, the recurrent cancers usually are amenable to further endoscopic eradication therapy. 
It remains unclear whether the excellent results for endoscopic eradication therapy reported by the few expert centers that have studied those techniques can be reproduced in the community. The durability of the eradication therapy, the frequency and importance of buried metaplasia, and the long-term efficacy of ablation therapy for cancer prevention remain unsettled issues. With those caveats, we conclude that endoscopic eradication therapy is a reasonable therapeutic option for patients with high-grade dysplasia in Barrett's esophagus, especially in those for whom advanced age or comorbid illness renders esophagectomy inordinately hazardous (see the following text). If endoscopic eradication therapy is to be used, we recommend that any visible abnormalities should be removed by EMR, which provides invaluable staging information as well as therapy, followed by the ablation of all remaining Barrett's metaplasia.

\section{Is Esophagectomy Still a Reasonable Option for Patients Who Have High-Grade Dysplasia in Barrett's Esophagus?}

For decades, esophagectomy had been the traditional treatment recommended for patients with high-grade dysplasia in Barrett's esophagus. ${ }^{86}$ For those patients, esophagectomy definitively eliminated all of the esophagus lined by Barrett's epithelium (dysplastic and nondysplastic) and, unlike modern endoscopic therapies, allowed for the removal of associated lymph nodes that could harbor metastases. Unfortunately, esophagectomy also could be associated with substantial rates of mortality and long-term morbidity. In some series of patients with esophageal cancer treated by esophagectomy, the operative mortality rate exceeded 20\%. Indeed, the burgeoning interest in endoscopic eradication therapy for dysplasia in Barrett's esophagus has been fueled largely by the perception that esophagectomy has unacceptably high rates of mortality and long-term morbidity (Table 3).

A number of studies have shown that mortality rates for esophagectomy are inversely related to the frequency with which the operation is performed at any given medical center. ${ }^{264}$ In a study of data from the Dutch National Medical Registry, for example, the mortality rates for esophagectomy were $12.1 \%, 7.5 \%$, and $4.9 \%$ at centers performing 1 to 10,11 to 20 , and $>50$ esophagectomies per year, respectively. ${ }^{265}$ Other reports have described esophagectomy mortality rates for high- and low-volume medical centers of $2.5 \%$ and $15.4 \%, 2662.7 \%$ and $16 \%,{ }^{267} 3.4 \%$ and $17.3 \%,{ }^{268} 4.8 \%$ and $16 \%,{ }^{269}$ and $8.4 \%$ and $20.3 \%,{ }^{270}$ respectively. Therefore, one way to reduce the mortality from esophagectomy is to have the operation performed by an experienced surgeon who practices in a center that has a high volume for esophagectomy.

Estimated mortality rates for esophagectomy have been based largely on series of patients who had the operation performed for the treatment of symptomatic esophageal cancers. ${ }^{86}$ Such patients are often elderly and debilitated by the dysphagia and anorexia that often accompany such advanced esophageal tumors. In addition to patients with adenocarcinoma in Barrett's esophagus, furthermore, those series often have included patients with squamous cell carcinoma of the esophagus, many of whom have had severe comorbid illnesses caused by the cigarette smoking and alcoholism associated with that tumor. One would anticipate substantially lower mortality rates for esophagectomy performed to treat dysplasia or early cancer in younger and otherwise healthy patients with Barrett's esophagus. In support of this notion, reports of a number of modern small series have described excellent survival rates when esophagectomy is performed primarily or exclusively for such patients (Table 4). ${ }^{271-300}$ Most of those studies have found no operative mortality, and none have described a mortality rate that exceeds $3.3 \%$.

Esophagectomy can cause distressing symptoms such as dysphagia, early satiety, loss of appetite, and fatigue, which can seriously impair quality of life. Most studies that have addressed specifically the issue of quality of life after esophagectomy have included 
primarily patients who had the operation because of advanced esophageal cancer, and the results of such studies may not be applicable to patients who undergo esophagectomy for asymptomatic neoplasia in Barrett's esophagus. Virtually all studies that have assessed quality of life in the immediate postoperative period have found that quality of life declines significantly immediately after esophagectomy. ${ }^{301}$ However, most, ${ }^{302-305}$ but not all, ${ }^{306,307}$ long-term studies also have found that the quality of life returns to or even exceeds baseline levels by 3 months to 2 years after esophagectomy. Other studies that have assessed longterm function, years after esophagectomy, have found that the patients' quality of life scores are similar to those of control subjects in the general population. ${ }^{308-310}$

Two studies have focused on quality of life primarily in patients who underwent esophagectomy for high-grade dysplasia or early cancer in Barrett's esophagus. One study of 34 such patients found that SF-36 results obtained at a mean follow-up of 46 months after esophagectomy were equal to or better than those of a healthy control population. ${ }^{279}$ The other study included 36 patients who had esophagectomy for high-grade dysplasia or intramucosal carcinoma and who were followed up for a mean duration of 4.9 years. Similar to the previous study, SF-36 scores for the patients were similar to those of age- and sexmatched control subjects. 278

Although esophagectomy generally is considered the most definitive of the therapeutic options for patients with dysplasia in Barrett's esophagus, new columnar metaplasia (cardia type and intestinal type) develops frequently in the esophageal remnant in patients who have had esophagectomy with esophagogastrostomy, presumably as a consequence of the reflux esophagitis that often accompanies this procedure. ${ }^{311-315}$ Conceivably, those patients might be at risk for developing adenocarcinoma in the neo-metaplastic epithelium, and there are rare case reports of such an occurrence. ${ }^{316-318}$ Nevertheless, the risk of carcinogenesis in the Barrett's epithelium that develops after esophagectomy appears to be very small.

In summary, esophagectomy for high-grade dysplasia in Barrett's esophagus definitively removes all of the esophagus at increased risk for malignancy (unlike limited EMR and endoscopic ablation), provides a specimen that can be examined for evidence of invasion (unlike endoscopic ablation), and obviates the concern that local lymph nodes might contain metastases (unlike EMR and ablation). When performed in otherwise healthy individuals with dysplasia in Barrett's esophagus, the mortality rate for the operation is substantially less than $5 \%$, and the long-term quality of life after esophagectomy is good in most cases. Thus, the option of esophagectomy still warrants serious consideration, especially for younger and otherwise fit patients who have high-grade dysplasia in Barrett's esophagus.

\section{Acknowledgments}

Funding Supported by the Office of Medical Research, Department of Veterans Affairs (R.F.S., S.J.S.), the National Institutes of Health (R01-DK63621 to R.F.S, R01-CA134571 to R.F.S. and S.J.S.), and the National Institutes of Health, National Institute of Diabetes and Digestive and Kidney Diseases (K24 DK080941 to J.M.I.).

\section{Appendix}

Search Algorithms Used in Systematic Reviews

\section{What Is the Definition of Barrett's Esophagus? What Landmark Identifies the Gastroesophageal Junction? What Epithelial Type Is Required for the}




\section{Diagnosis of Barrett's Esophagus? Should Endoscopists Measure the Extent of Barrett's Metaplasia?}

To identify relevant papers on the definition of Barrett's esophagus and the interrelated topics of identification of the gastroesophageal junction, histologic evaluation of esophageal biopsy samples for a determination of epithelial type, and measurement of the extent of Barrett's metaplasia, the text words "Barrett esophagus" were combined with the medical subject heading (MeSH) search terms "definition," "epithelium," "gastroesophageal junction," "esophagogastric junction," "diagnosis" (limited to title and abstract only), "extent," or "length." Relevant papers were selected from a yield of 1236.

\section{What Is the Risk of Esophageal Cancer for the General Population of Patients With Barrett's Esophagus? What Is the Natural History of Dysplasia in Barrett's Esophagus?}

To identify relevant papers on the progression and regression of patients with Barrett's esophagus with regard to dysplasia and esophageal adenocarcinoma, the search keywords "Barrett esophagus" or Barrett metaplasia" or "Barrett's mucosa" or "Barrett's epithelium" were combined with MeSH search terms "dysplasia" or "esophageal cancer" or "esophageal neoplasm." Relevant papers were selected from a yield of 305,425 references.

\section{Does Barrett's Esophagus Affect Life Expectancy? How Does a Diagnosis of Barrett's Esophagus Affect Quality of Life?}

To identify relevant papers on the impact of a diagnosis of Barrett's esophagus on life expectancy, the search keywords "Barrett esophagus" or Barrett's oesophagus" or "Barrett metaplasia" or "Barrett's mucosa" or "Barrett's epithelium" were combined with search keywords "life expectancy" or "mortality." Relevant papers were selected from a yield of 525 papers. Bibliographies of relevant articles were reviewed for additional pertinent manuscripts not encapsulated by the search. Reported data were retrospective cohort and case-control data reporting mortality. To define relevant papers on quality of life, we used the MeSH search terms "Barrett esophagus" and "quality of life" as well as the terms "Barrett's esophagus," "Barrett esophagus," "Barrett's," and "intestinal metaplasia" combined with the terms "quality of life," "QoL," "HRQoL," "SF-36," "QOLRAD," "GIQLI," "burden," and "economic impact." We also searched the MeSH search term "GERD" with the MeSH search term "quality of life" in addition to the term "Barrett's esophagus." Appropriate manuscripts were selected from 102 papers. We subsequently assessed the bibliographies of all identified relevant articles to identify data missed on the initial literature search. Reported studies were cohort studies, case series, or clinical trials.

\section{Who Is at Risk for Barrett's Esophagus? Who Should Be Screened for Barrett's Esophagus?}

To identify relevant papers on risk factors for Barrett's esophagus, the search keywords "Barrett esophagus" or Barrett's oesophagus" or "Barrett metaplasia" or "Barrett's mucosa" or "Barrett's epithelium" were combined with search keywords "risk factor" and "prevalence." Relevant papers were selected from 1932 citations. Regarding who should be screened for Barrett's esophagus, the search keywords "Barrett esophagus" or Barrett's oesophagus" or "Barrett metaplasia" or "Barrett's mucosa" or "Barrett's epithelium" were combined with the MeSH search term "screening." From 4597 citations, case-control studies, cohort data, and cross-sectional studies were retrieved. We subsequently assessed 
the bibliographies of all identified relevant articles to identify data missed on the initial literature search.

\section{Does Endoscopic Surveillance Improve Survival for Patients With Barrett's Esophagus?}

To identify relevant papers on the role of endoscopic surveillance on mortality from esophageal adenocarcinoma, the keywords "Barrett esophagus" or "esophageal" and "adenocarcinoma" were combined with MeSH search terms "mass screening" or "early detection of cancer" or "surveillance" or "endoscopy." Relevant papers were selected from a yield of 3250 references.

\section{Can Biomarkers Be Used to Confirm the Histologic Diagnosis of Dysplasia? Can Biomarkers Be Used Instead of Dysplasia for Risk Stratification in Barrett's Esophagus?}

To identify relevant papers on the role of biomarkers for confirming a diagnosis of dysplasia and for risk stratification in Barrett's esophagus, the text words "Barrett esophagus" were combined with the MeSH search terms "biomarker," "molecular," "mutation," "deletion," "heterozygosity," "gene," or "genetic.” Relevant papers were selected from a yield of 608.

\section{Should Chromoendoscopy or "Electronic Chromoendoscopy" Be Used to Enhance the Detection of Metaplasia and Dysplasia in Barrett's Esophagus?}

To identify relevant papers on the role of chromoendoscopy and related techniques for the yield of Barrett's esophagus and dysplasia, the following keywords and MeSH search terms were used: "Barrett esophagus" and "chromoendoscopy" or "electronic chromoendoscopy" or "narrow band imaging" or "FICE" or "NBI." Relevant papers were selected from a yield of 109 references.

\section{Should Advanced Endoscopic Imaging Techniques Such as Autofluorescence Imaging, Confocal Laser Endomicroscopy, Diffuse Reflectance and Light Scattering Spectroscopy, and Optical Coherence Tomography Be Used to Enhance the Detection of Metaplasia and Dysplasia in Barrett's Esophagus?}

To identify relevant papers on the role of spectroscopy, autofluorescence, confocal endomicroscopy, and related techniques for the yield of Barrett's esophagus and dysplasia, the following keywords and MeSH search terms were used: "Barrett esophagus" and ("adenocarcinoma" or "dysplasia" or "metaplasia") and ("advanced imaging" or "optical coherence" or "spectroscopy" or "reflectance" or "endomicroscopy" or "endoscopic imaging" or "imaging"). Relevant papers were selected from a yield of 1551 references. 


\title{
Should Proton Pump Inhibitors Be Used for Chemoprevention in Barrett's Esophagus? Should Nonsteroidal Anti-inflammatory Drugs Be Used for Chemoprevention in Barrett's Esophagus?
}

To identify relevant papers on the role of proton pump inhibitors and nonsteroidal antiinflammatory drugs for chemoprevention in Barrett's esophagus, the text words "Barrett esophagus" were combined with the MeSH search terms "proton pump inhibitor," "PPI," "nonsteroidal anti-inflammatory drugs," or "NSAID." Relevant papers were selected from a yield of 391.

\section{Should Antireflux Surgery Be Advised to Prevent Cancer in Barrett's Esophagus?}

To identify relevant papers on the role of antireflux surgery for cancer prevention in Barrett's esophagus, the text words "Barrett esophagus" were combined with the MeSH search terms "fundoplication," "antireflux surgery," or "cancer risk." Relevant papers were selected from a yield of 1214 .

\section{What Is the Role for EMR in Barrett's Esophagus? Should Endoscopic Eradication Be Used to Treat Patients Who Have Barrett's Esophagus Without Dysplasia? Should Endoscopic Eradication Be Used to Treat Patients Who Have Barrett's Esophagus With Low-Grade Dysplasia? Should Endoscopic Eradication Be Used to Treat Patients Who Have Barrett's Esophagus With High-Grade Dysplasia or Intramucosal Carcinoma?}

To identify relevant papers on the role of endoscopic therapies on the treatment of Barrett's esophagus, dysplasia, and esophageal adenocarcinoma, the following keywords and $\mathrm{MeSH}$ search terms were used: "Barrett esophagus" and ("adenocarcinoma" or "dysplasia") and ("endoscopic mucosal resection" OR "ablation" OR "endoscop*” OR "therap*"). Relevant papers were selected from a yield of 382 references.

\section{Is Esophagectomy Still a Reasonable Option for Patients Who Have High- Grade Dysplasia in Barrett's Esophagus?}

To identify relevant papers on the role of esophagectomy for patients with high-grade dysplasia in Barrett's esophagus, the text words "Barrett esophagus" were combined with the MeSH search terms "esophagectomy," "resection," or "dysplasia." Relevant papers were selected from a yield of 1516 .

\author{
Abbreviations used in this paper \\ AFI autofluorescence imaging \\ AGAI American Gastroenterological Association Institute \\ APC argon plasma coagulation \\ CI confidence interval
}




$\begin{array}{ll}\text { CPQMC } & \text { Clinical Practice and Quality Management Committee } \\ \text { EMR } & \text { endoscopic mucosal resection } \\ \text { EUS } & \text { endoscopic ultrasonography } \\ \text { GEJ } & \text { gastroesophageal junction } \\ \text { GERD } & \text { gastroesophageal reflux disease } \\ \text { GRADE } & \text { Grading of Recommendations Assessment, Development and Evaluation } \\ \text { LOH } & \text { loss of heterozygosity } \\ \text { PEC } & \text { multi-polar electrocoagulation } \\ \text { NBI } & \text { narrow band imaging } \\ \text { PDT } & \text { photodynamic therapy } \\ \text { PPI } & \text { proton pump inhibitor } \\ \text { QOLRAD } & \text { Quality of Life in Reflux and Dyspepsia } \\ \text { RFA } & \text { radiofrequency ablation } \\ \text { RR } & \text { relative risk } \\ \text { SEER } & \text { Surveillance, Epidemiology and End Results } \\ \text { SF-36 } & \text { 36-Item Short Form Health Survey } \\ \text { TR } & \text { technical review }\end{array}$

\section{References}

1. Sharma P, McQuaid K, Dent J, et al. AGA Chicago Workshop. A critical review of the diagnosis and management of Barrett's esophagus: the AGA Chicago Workshop. Gastroenterology. 2004; 127:310-330. [PubMed: 15236196]

2. Vakil N, van Zanten SV, Kahrilas P, et al. Global Consensus Group. The Montreal definition and classification of gastroesophageal reflux disease: a global evidence-based consensus. Am J Gastroenterol. 2006; 101:1900-1920. [PubMed: 16928254]

3. Wang KK, Sampliner RE, Practice Parameters Committee of the American College of Gastroenterology. Updated guidelines 2008 for the diagnosis, surveillance and therapy of Barrett's esophagus. Am J Gastroenterol. 2008; 103:788-797. [PubMed: 18341497]

4. Shaheen NJ, Richter JE. Barrett's oesophagus. Lancet. 2009; 373:850-861. [PubMed: 19269522]

5. McClave SA, Boyce HW Jr, Gottfried MR. Early diagnosis of columnar-lined esophagus: a new endoscopic criterion. Gastrointest Endosc. 1987; 33:413-416. [PubMed: 3443258]

6. Choi do W, Oh SN, Baek SJ, et al. Endoscopically observed lower esophageal capillary patterns. Korean J Intern Med. 2002; 17:245-248. [PubMed: 12647639]

7. Vianna A, Hayes PC, Moscoso G, et al. Normal venous circulation of the gastroesophageal junction. A route to understanding varices. Gastroenterology. 1987; 93:876-889. [PubMed: 3623028]

8. Paull A, Trier JS, Dalton MD, et al. The histologic spectrum of Barrett's esophagus. N Engl J Med. 1976; 295:476-480. [PubMed: 940579]

9. Hayward J. The lower end of the oesophagus. Thorax. 1961; 16:36-41. [PubMed: 13712529]

10. Spechler SJ. Intestinal metaplasia at the gastroesophageal junction. Gastroenterology. 2004; 126:567-575. [PubMed: 14762793]

11. Chandrasoma P. Pathophysiology of Barrett's esophagus. Semin Thorac Cardiovasc Surg. 1997; 9:270-278. [PubMed: 9263345] 
12. Liu W, Hahn H, Odze RD, et al. Metaplastic esophageal columnar epithelium without goblet cells shows DNA content abnormalities similar to goblet cell-containing epithelium. Am J Gastroenterol. 2009; 104:816-824. [PubMed: 19293780]

13. Hahn HP, Blount PL, Ayub K, et al. Intestinal differentiation in metaplastic, nongoblet columnar epithelium in the esophagus. Am J Surg Pathol. 2009; 33:1006-1015. [PubMed: 19363439]

14. Takubo K, Aida J, Naomoto Y, et al. Cardiac rather than intestinal-type background in endoscopic resection specimens of minute Barrett adenocarcinoma. Hum Pathol. 2009; 40:65-74. [PubMed: 18755496]

15. Shaheen NJ, Crosby MA, Bozymski EM, et al. Is there publication bias in the reporting of cancer risk in Barrett's esophagus? Gastroenterology. 2000; 119:333-338. [PubMed: 10930368]

16. Sharma P, Morales TG, Sampliner RE. Short segment Barrett's esophagus. The need for standardization of the definition and of endoscopic criteria. Am J Gastroenterol. 1998; 93:10331036. [PubMed: 9672325]

17. Sharma P, Dent J, Armstrong D, et al. The development and validation of an endoscopic grading system for Barrett's esophagus: the Prague C \& M criteria. Gastroenterology. 2006; 131:13921399. [PubMed: 17101315]

18. Robertson CS, Mayberry JF, Nicholson DA, et al. Value of endoscopic surveillance in the detection of neoplastic change in Barrett's oesophagus. Br J Surg. 1988; 75:760-763. [PubMed: 3167523]

19. Reid BJ, Blount PL, Rubin CE, et al. Flow-cytometric and histological progression to malignancy in Barrett's esophagus: prospective endoscopic surveillance of a cohort. Gastroenterology. 1992; 102:1212-1219. [PubMed: 1551528]

20. Bartlesman JF, Hameeteman W, Tytgat GN. Barrett's oesophagus. Eur J Cancer Prev. 1992; 1:323-325. [PubMed: 1467782]

21. Aldulaimi DM, Cox M, Nwokolo CU, et al. Barrett's surveillance is worthwhile and detects curable cancers. A prospective cohort study addressing cancer incidence, treatment outcome and survival. Eur J Gastroenterol Hepatol. 2005; 17:943-950. [PubMed: 16093872]

22. Chang EY, Morris CD, Seltman AK, et al. The effect of antireflux surgery on esophageal carcinogenesis in patients with Barrett esophagus: a systematic review. Ann Surg. 2007; 246:1121. [PubMed: 17592284]

23. Thomas T, Abrams KR, De Caestecker JS, et al. Meta analysis: cancer risk in Barrett's oesophagus. Aliment Pharmacol Ther. 2007; 26:1465-1477. [PubMed: 17900269]

24. Yousef F, Cardwell C, Cantwell MM, et al. The incidence of esophageal cancer and high-grade dysplasia in Barrett's esophagus: a systematic review and meta-analysis. Am J Epidemiol. 2008; 168:237-249. [PubMed: 18550563]

25. Cook MB, Wild CP, Everett SM, et al. Risk of mortality and cancer incidence in Barrett's esophagus. Cancer Epidemiol Biomarkers Prev. 2007; 16:2090-2096. [PubMed: 17890521]

26. Cooper BT, Chapman W, Neumann CS, et al. Continuous treatment of Barrett's oesophagus patients with proton pump inhibitors up to 13 years: observations on regression and cancer incidence. Aliment Pharmacol Ther. 2006; 23:727-733. [PubMed: 16556174]

27. Gatenby PA, Ramus JR, Caygill CP, et al. Treatment modality and risk of development of dysplasia and adenocarcinoma in columnar-lined esophagus. Dis Esophagus. 2009; 22:133-142. [PubMed: 19018855]

28. Alcedo J, Ferrandez A, Arenas J, et al. Trends in Barrett's esophagus diagnosis in Southern Europe: implications for surveillance. Dis Esophagus. 2009; 22:239-248. [PubMed: 19425201]

29. Anderson LA, Murray LJ, Murphy SJ, et al. Mortality in Barrett's oesophagus: results from a population based study. Gut. 2003; 52:1081-1084. [PubMed: 12865262]

30. Eckardt VF, Kanzler G, Bernhard G. Life expectancy and cancer risk in patients with Barrett's esophagus: a prospective controlled investigation. Am J Med. 2001; 111:33-37. [PubMed: 11448658]

31. Moayyedi P, Burch N, Akhtar-Danesh N, et al. Mortality rates in patients with Barrett's oesophagus. Aliment Pharmacol Ther. 2008; 27:316-320. [PubMed: 18062791] 
32. Solaymani-Dodaran M, Logan RF, West J, et al. Mortality associated with Barrett's esophagus and gastroesophageal reflux disease diagnoses-a population-based cohort study. Am J Gastroenterol. 2005; 100:2616-2621. [PubMed: 16393209]

33. Rana PS, Johnston DA. Incidence of adenocarcinoma and mortality in patients with Barrett's oesophagus diagnosed between 1976 and 1986: implications for endoscopic surveillance. Dis Esophagus. 2000; 13:28-31. [PubMed: 11005328]

34. Van der Burgh A, Dees J, Hop WC, et al. Oesophageal cancer is an uncommon cause of death in patients with Barrett's oesophagus. Gut. 1996; 39:5-8. [PubMed: 8881798]

35. Mayne ST, Risch HA, Dubrow R, et al. Nutrient intake and risk of subtypes of esophageal and gastric cancer. Cancer Epidemiol Biomarkers Prev. 2001; 10:1055-1062. [PubMed: 11588131]

36. Crockett SD, Lippmann QK, Dellon ES, et al. Health-related quality of life in patients with Barrett's esophagus: a systematic review. Clin Gastroenterol Hepatol. 2009; 7:613-623. [PubMed: 19281858]

37. Ware JE Jr, Sherbourne CD. The MOS 36-item short-form health survey (SF-36). I. Conceptual framework and item selection. Med Care. 1992; 30:473-483. [PubMed: 1593914]

38. Wiklund IK, Junghard O, Grace E, et al. Quality of Life in Reflux and Dyspepsia patients. Psychometric documentation of a new disease-specific questionnaire (QOLRAD). Eur J Surg Suppl. 1998; (583):41-49. [PubMed: 10027672]

39. Eypasch E, Williams JI, Wood-Dauphinee S, et al. Gastrointestinal Quality of Life Index: development, validation and application of a new instrument. Br J Surg. 1995; 82:216-222. [PubMed: 7749697]

40. Gerson LB, Ullah N, Hastie T, et al. Does cancer risk affect health-related quality of life in patients with Barrett's esophagus? Gastrointest Endosc. 2007; 65:16-25. [PubMed: 17185075]

41. Shaheen NJ, Green B, Medapalli RK, et al. The perception of cancer risk in patients with prevalent Barrett's esophagus enrolled in an endoscopic surveillance program. Gastroenterology. 2005; 129:429-436. [PubMed: 16083700]

42. Shaheen NJ, Dulai GS, Ascher B, et al. Effect of a new diagnosis of Barrett's esophagus on insurance status. Am J Gastroenterol. 2005; 100:577-580. [PubMed: 15743354]

43. Abrams JA, Fields S, Lightdale CJ, et al. Racial and ethnic disparities in the prevalence of Barrett's esophagus among patients who undergo upper endoscopy. Clin Gastroenterol Hepatol. 2008; 6:30-34. [PubMed: 18063419]

44. Edelstein ZR, Bronner MP, Rosen SN, et al. Risk factors for Barrett's esophagus among patients with gastroesophageal reflux disease: a community clinic-based case-control study. Am J Gastroenterol. 2009; 104:834-842. [PubMed: 19319131]

45. Cooper BT, Chapman W, Neumann CS, et al. Continuous treatment of Barrett's oesophagus patients with proton pump inhibitors up to 13 years: observations on regression and cancer incidence. Aliment Pharmacol Ther. 2006; 23:727-733. [PubMed: 16556174]

46. Campos GM, DeMeester SR, Peters JH, et al. Predictive factors of Barrett esophagus: multivariate analysis of 502 patients with gastroesophageal reflux disease. Arch Surg. 2001; 136:1267-1273. [PubMed: 11695971]

47. Falk GW, Thota PN, Richter JE, et al. Barrett's esophagus in women: demographic features and progression to high-grade dysplasia and cancer. Clin Gastroenterol Hepatol. 2005; 3:1089-1094. [PubMed: 16271339]

48. Corley DA, Kubo A, Levin TR, et al. Race, ethnicity, sex and temporal differences in Barrett's oesophagus diagnosis: a large community-based study, 1994-2006. Gut. 2009; 58:182-188. [PubMed: 18978173]

49. Cook MB, Wild CP, Forman D. A systematic review and meta-analysis of the sex ratio for Barrett's esophagus, erosive reflux disease, and nonerosive reflux disease. Am J Epidemiol. 2005; 162:1050-1061. [PubMed: 16221805]

50. Rex DK, Cummings OW, Shaw M, et al. Screening for Barrett's esophagus in colonoscopy patients with and without heartburn. Gastroenterology. 2003; 125:1670-1677. [PubMed: 14724819]

51. Eloubeidi MA, Provenzale D. Clinical and demographic predictors of Barrett's esophagus among patients with gastroesophageal reflux disease: a multivariable analysis in veterans. J Clin Gastroenterol. 2001; 33:306-309. [PubMed: 11588545] 
52. Srinivasan R, Tutuian R, Schoenfeld P, et al. Profile of GERD in the adult population of a northeast urban community. J Clin Gastroenterol. 2004; 38:651-657. [PubMed: 15319646]

53. Spechler SJ, Jain SK, Tendler DA, et al. Racial differences in the frequency of symptoms and complications of gastro-oesophageal reflux disease. Aliment Pharmacol Ther. 2002; 16:17951800. [PubMed: 12269973]

54. Eisen GM, Sandler RS, Murray S, et al. The relationship between gastroesophageal reflux disease and its complications with Barrett's esophagus [see comments]. Am J Gastroenterol. 1997; 92:2731. [PubMed: 8995932]

55. Avidan B, Sonnenberg A, Schnell TG, et al. Hiatal hernia and acid reflux frequency predict presence and length of Barrett's esophagus. Dig Dis Sci. 2002; 47:256-264. [PubMed: 11855539]

56. Smith KJ, O'Brien SM, Smithers BM, et al. Interactions among smoking, obesity, and symptoms of acid reflux in Barrett's esophagus. Cancer Epidemiol Biomarkers Prev. 2005; 14:2481-2486. [PubMed: 16284367]

57. Lieberman DA, Oehlke M, Helfand M. Risk factors for Barrett's esophagus in community-based practice. GORGE consortium. Gastroenterology Outcomes Research Group in Endoscopy. Am J Gastroenterol. 1997; 92:1293-1297. [PubMed: 9260792]

58. Monaco L, Brillantino A, Torelli F, et al. Prevalence of bile reflux in gastroesophageal reflux disease patients not responsive to proton pump inhibitors. World J Gastroenterol. 2009; 15:334338. [PubMed: 19140233]

59. Edelstein ZR, Farrow DC, Bronner MP, et al. Central adiposity and risk of Barrett's esophagus. Gastroenterology. 2007; 133:403-411. [PubMed: 17681161]

60. El Serag HB, Kvapil P, Hacken-Bitar J, et al. Abdominal obesity and the risk of Barrett's esophagus. Am J Gastroenterol. 2005; 100:2151-2156. [PubMed: 16181362]

61. Kamat P, Wen S, Morris J, et al. Exploring the association between elevated body mass index and Barrett's esophagus: a systematic review and meta-analysis. Ann Thorac Surg. 2009; 87:655-662. [PubMed: 19161814]

62. Corley DA, Kubo A, Levin TR, et al. Abdominal obesity and body mass index as risk factors for Barrett's esophagus. Gastroenterology. 2007; 133:34-41. [PubMed: 17631128]

63. Ronkainen J, Aro P, Storskrubb T, et al. Prevalence of Barrett's esophagus in the general population: an endoscopic study. Gastroenterology. 2005; 129:1825-1831. [PubMed: 16344051]

64. Akiyama $\mathrm{T}$, Inamori $\mathrm{M}$, Iida $\mathrm{H}$, et al. Alcohol consumption is associated with an increased risk of erosive esophagitis and Barrett's epithelium in Japanese men. BMC Gastroenterol. 2008; 8:58. [PubMed: 19077221]

65. Anderson LA, Cantwell MM, Watson RG, et al. The association between alcohol and reflux esophagitis, Barrett's esophagus, and esophageal adenocarcinoma. Gastroenterology. 2009; 136:799-805. [PubMed: 19162028]

66. Kubo A, Levin TR, Block G, et al. Alcohol types and sociodemographic characteristics as risk factors for Barrett's esophagus. Gastroenterology. 2009; 136:806-815. [PubMed: 19111726]

67. Kubo A, Levin TR, Block G, et al. Cigarette smoking and the risk of Barrett's esophagus. Cancer Causes Control. 2009; 20:303-311. [PubMed: 18853262]

68. Thompson OM, Beresford SA, Kirk EA, et al. Vegetable and fruit intakes and risk of Barrett's esophagus in men and women. Am J Clin Nutr. 2009; 89:890-896. [PubMed: 19144726]

69. Kubo A, Levin TR, Block G, et al. Dietary patterns and the risk of Barrett's esophagus. Am J Epidemiol. 2008; 167:839-846. [PubMed: 18218607]

70. Rubenstein JH, Saini SD, Kuhn L, et al. Influence of malpractice history on the practice of screening and surveillance for Barrett's esophagus. Am J Gastroenterol. 2008; 103:842-849. [PubMed: 18076733]

71. Hirota WK, Zuckerman MJ, Adler DG, et al. ASGE guideline: the role of endoscopy in the surveillance of premalignant conditions of the upper GI tract. Gastrointest Endosc. 2006; 63:570580. [PubMed: 16564854]

72. Wang KK, Sampliner RE. Updated guidelines 2008 for the diagnosis, surveillance and therapy of Barrett's esophagus. Am J Gastroenterol. 2008; 103:788-797. [PubMed: 18341497]

73. Playford RJ. New British Society of Gastroenterology (BSG) guidelines for the diagnosis and management of Barrett's oesophagus. Gut. 2006; 55:442. [PubMed: 16531521] 
74. Corley DA, Levin TR, Habel LA, et al. Surveillance and survival in Barrett's adenocarcinomas: a population-based study. Gastroenterology. 2002; 122:633-640. [PubMed: 11874995]

75. Van Sandick JW, van Lanschot JJ, Kuiken BW, et al. Impact of endoscopic biopsy surveillance of Barrett's oesophagus on pathological stage and clinical outcome of Barrett's carcinoma. Gut. 1998; 43:216-222. [PubMed: 10189847]

76. Inadomi JM, Sampliner R, Lagergren J, et al. Screening and surveillance for Barrett esophagus in high-risk groups: a cost-utility analysis [comment]. Ann Intern Med. 2003; 138:176-186. [PubMed: 12558356]

77. Provenzale D, Schmitt C, Wong JB. Barrett's esophagus: a new look at surveillance based on emerging estimates of cancer risk. Am J Gastroenterol. 1999; 94:2043-2053. [PubMed: 10445526]

78. Lagergren J, Bergstrom R, Lindgren A, et al. Symptomatic gastroesophageal reflux as a risk factor for esophageal adenocarcinoma. N Engl J Med. 1999; 340:825-831. [PubMed: 10080844]

79. Locke GR III, Talley NJ, Fett SL, et al. Prevalence and clinical spectrum of gastroesophageal reflux: a population-based study in Olmsted County, Minnesota. Gastroenterology. 1997; 112:1448-1456. [PubMed: 9136821]

80. Pohl H, Welch HG. The role of overdiagnosis and reclassification in the marked increase of esophageal adenocarcinoma incidence. J Natl Cancer Inst. 2005; 97:142-146. [PubMed: 15657344]

81. Schnell TG, Sontag SJ, Chejfec G, et al. Long-term nonsurgical management of Barrett's esophagus with high-grade dysplasia. Gastroenterology. 2001; 120:1607-1619. [PubMed: 11375943]

82. Eloubeidi MA, Provenzale D. Does this patient have Barrett's esophagus? The utility of predicting Barrett's esophagus at the index endoscopy. Am J Gastroenterol. 1999; 94:937-943. [PubMed: 10201460]

83. Chatelain D, Flejou JF. High-grade dysplasia and superficial adenocarcinoma in Barrett's esophagus: histological mapping and expression of p53, p21 and Bcl-2 oncoproteins. Virchows Arch. 2003; 442:18-24. [PubMed: 12536310]

84. Montgomery E, Bronner MP, Goldblum JR, et al. Reproducibility of the diagnosis of dysplasia in Barrett esophagus: a reaffirmation. Hum Pathol. 2001; 32:368-378. [PubMed: 11331953]

85. Shaheen NJ, Provenzale D. Screening strategies in gastroesophageal reflux disease: early identification of esophageal carcinoma. Adv Intern Med. 2001; 47:137-157. [PubMed: 11795073]

86. Spechler SJ. Dysplasia in Barrett's esophagus: limitations of current management strategies. Am J Gastroenterol. 2005; 100:927-935. [PubMed: 15784042]

87. Collard JM. High-grade dysplasia in Barrett's esophagus. The case for esophagectomy. Chest Surg Clin North Am. 2002; 12:77-92.

88. Konda VJ, Ross AS, Ferguson MK, et al. Is the risk of concomitant invasive esophageal cancer in high-grade dysplasia in Barrett's esophagus overestimated? Clin Gastroenterol Hepatol. 2008; 6:159-164. [PubMed: 18096439]

89. Rastogi A, Puli S, El-Serag HB, et al. Incidence of esophageal adenocarcinoma in patients with Barrett's esophagus and high-grade dysplasia: a meta-analysis. Gastrointest Endosc. 2008; 67:394398. [PubMed: 18045592]

90. Schnell TG, Sontag SJ, Chejfec G, et al. Long-term nonsurgical management of Barrett's esophagus with high-grade dysplasia. Gastroenterology. 2001; 120:1607-1619. [PubMed: 11375943]

91. Reid BJ, Levine DS, Longton G, et al. Predictors of progression to cancer in Barrett's esophagus: baseline histology and flow cytometry identify low- and high-risk patient subsets. Am J Gastroenterol. 2000; 95:1669-1676. [PubMed: 10925966]

92. Sharma P, Falk GW, Weston AP, et al. Dysplasia and cancer in a large multicenter cohort of patients with Barrett's esophagus. Clin Gastroenterol Hepatol. 2006; 4:566-572. [PubMed: 16630761]

93. Montgomery E, Goldblum JR, Greenson JK, et al. Dysplasia as a predictive marker for invasive carcinoma in Barrett esophagus: A follow-up study based on 138 cases from a diagnostic variability study. Hum Pathol. 2001; 32:379-388. [PubMed: 11331954] 
94. Sharma P. Low-grade dysplasia in Barrett's esophagus. Gastroenterology. 2004; 127:1233-1238. [PubMed: 15481000]

95. Srivastava A, Hornick JL, Li X, et al. Extent of low-grade dysplasia is a risk factor for the development of esophageal adenocarcinoma in Barrett's esophagus. Am J Gastroenterol. 2007; 102:483-493. [PubMed: 17338734]

96. Fitzgerald RC, Saeed IT, Khoo D, et al. Rigorous surveillance protocol increases detection of curable cancers associated with Barrett's esophagus. Dig Dis Sci. 2001; 46:1892-1898. [PubMed: $11575441]$

97. Curvers WL, Peters FP, Elzer B, et al. Quality of Barrett's surveillance in The Netherlands: a standardized review of endoscopy and pathology reports. Eur J Gastroenterol Hepatol. 2008; 20:601-607. [PubMed: 18679060]

98. Abrams JA, Kapel RC, Lindberg GM, et al. Adherence to biopsy guidelines for Barrett's esophagus surveillance in the community setting in the United States. Clin Gastroenterol Hepatol. 2009; 7:736-742. [PubMed: 19268726]

99. Streitz JM Jr, Andrews CW Jr, Ellis FH Jr. Endoscopic surveillance of Barrett's esophagus. Does it help? J Thorac Cardiovasc Surg. 1993; 105:383-387. [PubMed: 8445916]

100. Peters JH, Clark GW, Ireland AP, et al. Outcome of adenocarcinoma arising in Barrett's esophagus in endoscopically surveyed and nonsurveyed patients. J Thorac Cardiovasc Surg. 1994; 108:813-821. [PubMed: 7967662]

101. Fountoulakis A, Zafirellis KD, Dolan K, et al. Effect of surveillance of Barrett's oesophagus on the clinical outcome of oesophageal cancer. Br J Surg. 2004; 91:997-1003. [PubMed: 15286961]

102. Cooper GS, Yuan Z, Chak A, et al. Association of prediagnosis endoscopy with stage and survival in adenocarcinoma of the esophagus and gastric cardia. Cancer. 2002; 95:32-38. [PubMed: 12115314]

103. Cooper GS, Kou TD, Chak A. Receipt of previous diagnoses and endoscopy and outcome from esophageal adenocarcinoma: a population-based study with temporal trends. Am J Gastroenterol. 2009; 104:1356-1362. [PubMed: 19491849]

104. Kearney DJ, Crump C, Maynard C, et al. A case-control study of endoscopy and mortality from adenocarcinoma of the esophagus or gastric cardia in persons with GERD. Gastrointest Endosc. 2003; 57:823-829. [PubMed: 12776027]

105. Rubenstein JH, Sonnenberg A, Davis J, et al. Effect of a prior endoscopy on outcomes of esophageal adenocarcinoma among United States veterans. Gastrointest Endosc. 2008; 68:849_ 855. [PubMed: 18547567]

106. Reid BJ, Haggitt RC, Rubin CE, et al. Observer variation in the diagnosis of dysplasia in Barrett's esophagus. Hum Pathol. 1988; 19:166-178. [PubMed: 3343032]

107. Downs-Kelly E, Mendelin JE, Bennett AE, et al. Poor interobserver agreement in the distinction of high-grade dysplasia and adenocarcinoma in pretreatment Barrett's esophagus biopsies. Am J Gastroenterol. 2008; 103:2333-2340. [PubMed: 18671819]

108. Odze RD. Diagnosis and grading of dysplasia in Barrett's oesophagus. J Clin Pathol. 2006; 59:1029-1038. [PubMed: 17021130]

109. van Dekken H, Hop WC, Tilanus HW, et al. Immunohistochemical evaluation of a panel of tumor cell markers during malignant progression in Barrett esophagus. Am J Clin Pathol. 2008; 130:745-753. [PubMed: 18854267]

110. Dorer R, Odze RD. AMACR immunostaining is useful in detecting dysplastic epithelium in Barrett's esophagus, ulcerative colitis, and Crohn's disease. Am J Surg Pathol. 2006; 30:871-877. [PubMed: 16819330]

111. Shi XY, Bhagwandeen B, Leong AS. p16, cyclin D1, Ki-67, and AMACR as markers for dysplasia in Barrett esophagus. Appl Immunohistochem Mol Morphol. 2008; 16:447-452. [PubMed: 18665038]

112. Hennig EE, Mikula M, Orlowska J, et al. Large intra- and inter-individual variability of genes expression levels limits potential predictive value of molecular diagnosis of dysplasia in Barrett's esophagus. J Mol Med. 2008; 86:233-242. [PubMed: 17952395] 
113. Reid BJ, Levine DS, Longton G, et al. Predictors of progression to cancer in Barrett's esophagus: baseline histology and flow cytometry identify low- and high-risk patient subsets. Am J Gastroenterol. 2000; 95:1669-1676. [PubMed: 10925966]

114. Rabinovitch PS, Longton G, Blount PL, et al. Predictors of progression in Barrett's esophagus III: baseline flow cytometric variables. Am J Gastroenterol. 2001; 96:3071-3083. [PubMed: 11721752]

115. Kerkhof M, Steyerberg EW, Kusters JG, et al. Aneuploidy and high expression of p53 and Ki67 is associated with neoplastic progression in Barrett esophagus. Cancer Biomark. 2008; 4:1-10. [PubMed: 18334729]

116. Huang Q, Yu C, Zhang X, et al. Comparison of DNA histograms by standard flow cytometry and image cytometry on sections in Barrett's adenocarcinoma. BMC Clin Pathol. 2008; 8:5. [PubMed: 18513411]

117. Rygiel AM, Milano F, Ten Kate FJ, et al. Assessment of chromosomal gains as compared to DNA content changes is more useful to detect dysplasia in Barrett's esophagus brush cytology specimens. Genes Chromosomes Cancer. 2008; 47:396-404. [PubMed: 18265409]

118. Reid BJ, Prevo LJ, Galipeau PC, et al. Predictors of progression in Barrett's esophagus II: baseline 17p (p53) loss of heterozygosity identifies a patient subset at increased risk for neoplastic progression. Am J Gastroenterol. 2001; 96:2839-2848. [PubMed: 11693316]

119. Galipeau PC, Li X, Blount PL, et al. NSAIDs modulate CDKN2A, TP53, and DNA content risk for progression to esophageal adenocarcinoma. PLoS Med. 2007; 4:e67. [PubMed: 17326708]

120. Fahmy M, Skacel M, Gramlich TL, et al. Chromosomal gains and genomic loss of p53 and p16 genes in Barrett's esophagus detected by fluorescence in situ hybridization of cytology specimens. Mod Pathol. 2004; 17:588-596. [PubMed: 15017433]

121. Wongsurawat VJ, Finley JC, Galipeau PC, et al. Genetic mechanisms of TP53 loss of heterozygosity in Barrett's esophagus: implications for biomarker validation. Cancer Epidemiol Biomarkers Prev. 2006; 15:509-516. [PubMed: 16537709]

122. Cestari R, Villanacci V, Rossi E, et al. Fluorescence in situ hybridization to evaluate dysplasia in Barrett's esophagus: a pilot study. Cancer Lett. 2007; 251:278-287. [PubMed: 17321043]

123. Rygiel AM, van Baal JW, Milano F, et al. Efficient automated assessment of genetic abnormalities detected by fluorescence in situ hybridization on brush cytology in a Barrett esophagus surveillance population. Cancer. 2007; 109:1980-1988. [PubMed: 17385213]

124. Schulmann K, Sterian A, Berki A, et al. Inactivation of p16, RUNX3, and HPP1 occurs early in Barrett's-associated neoplastic progression and predicts progression risk. Oncogene. 2005; 24:4138-4148. [PubMed: 15824739]

125. Jin Z, Cheng Y, Gu W, et al. A multicenter, double-blinded validation study of methylation biomarkers for progression prediction in Barrett's esophagus. Cancer Res. 2009; 69:4112-4115. [PubMed: 19435894]

126. Nelson DB, Block KP, Bosco JJ, et al. High resolution and high-magnification endoscopy: September 2000. Gastrointest Endosc. 2000; 52:864-866. [PubMed: 11182692]

127. Sharma P. Magnification endoscopy. Gastrointest Endosc. 2005; 61:435-443. [PubMed: 15758921]

128. Yao K, Takaki Y, Ohara J, et al. Magnification endoscopy outlines the microvascular architecture and extent of Barrett's intramucosal carcinoma prior to endoscopic resection. Gastrointest Endosc. 2006; 63:1064-1065. [PubMed: 16733128]

129. Wani S, Sharma P. Endoscopic surface imaging of Barrett's esophagus: an optimistic view. Gastroenterology. 2007; 133:11-13. [PubMed: 17631123]

130. Kara MA, Smits ME, Rosmolen WD, et al. A randomized cross-over study comparing lightinduced fluorescence endoscopy with standard video endoscopy for the detection of early neoplasia in Barrett's esophagus. Gastrointest Endosc. 2005; 61:671-678. [PubMed: 15855970]

131. Kara MA, Peters FP, Rosmolen WD, et al. High-resolution endoscopy plus chromoendoscopy or narrow-band imaging in Barrett's esophagus: a prospective randomized crossover study. Endoscopy. 2005; 37:929-936. [PubMed: 16189764] 
132. Canto MI, Setrakian S, Willis JE, et al. Methylene blue staining of dysplastic and nondysplastic Barrett's esophagus: an in vivo and ex vivo study. Endoscopy. 2001; 33:391-400. [PubMed: 11396755]

133. Sharma P, Topalovski M, Mayo MS, et al. Methylene blue chromoendoscopy for detection of short-segment Barrett's esophagus. Gastrointest Endosc. 2001; 54:289-293. [PubMed: 11522967]

134. Breyer HP, Silva De Barros SG, Maguilnik I, et al. Does methylene blue detect intestinal metaplasia in Barrett's esophagus? Gastrointest Endosc. 2003; 57:505-509. [PubMed: 12665760]

135. Horwhat JD, Maydonovitch CL, Ramos F, et al. A randomized comparison of methylene bluedirected biopsy versus conventional four-quadrant biopsy for the detection of intestinal metaplasia and dysplasia in patients with long-segment Barrett's esophagus. Am J Gastroenterol. 2008; 103:546-554. [PubMed: 17970838]

136. Lim CH, Rotimi O, Dexter SP, et al. Randomized crossover study that used methylene blue or random 4-quadrant biopsy for the diagnosis of dysplasia in Barrett's esophagus. Gastrointest Endosc. 2006; 64:195-199. [PubMed: 16860068]

137. Meining A, Rösch T, Kiesslich R, et al. Inter- and intra-observer variability of magnification chromoendoscopy for detecting specialized intestinal metaplasia at the gastroesophageal junction. Endoscopy. 2004; 36:160-164. [PubMed: 14765313]

138. Sharma P, Weston AP, Topalovski M, et al. Magnification chromoendoscopy for the detection of intestinal metaplasia and dysplasia in Barrett's oesophagus. Gut. 2003; 52:24-27. [PubMed: 12477754]

139. Guelrud M, Herrera I. Acetic acid improves identification of remnant islands of Barrett's epithelium after endoscopic therapy. Gastrointest Endosc. 1998; 47:512-515. [PubMed: 9647377]

140. Ngamruengphong S, Sharma VK, Das A. Diagnostic yield of methylene blue chromoendoscopy for detecting specialized intestinal metaplasia and dysplasia in Barrett's esophagus: a metaanalysis. Gastrointest Endosc. 2009; 69:1021-1028. [PubMed: 19215918]

141. Guelrud M, Herrera I, Essenfeld H, et al. Enhanced magnification endoscopy: a new technique to identify specialized intestinal metaplasia in Barrett's esophagus. Gastrointest Endosc. 2001; 53:559-565. [PubMed: 11323579]

142. Olliver JR, Wild CP, Sahay P, et al. Chromoendoscopy with methylene blue and associated DNA damage in Barrett's oesophagus. Lancet. 2003; 362:373-374. [PubMed: 12907012]

143. Gono K, Obi T, Yamaguchi M, et al. Appearance of enhanced tissue features in narrow-band endoscopic imaging. J Biomed Opt. 2004; 9:568-577. [PubMed: 15189095]

144. Pohl J, May A, Rabenstein T, et al. Comparison of computed virtual chromoendoscopy and conventional chromoendoscopy with acetic acid for detection of neoplasia in Barrett's esophagus. Endoscopy. 2007; 39:594-598. [PubMed: 17611913]

145. Sharma P, Bansal A, Mathur S, et al. The utility of a novel narrow band imaging endoscopy system in patients with Barrett's esophagus. Gastrointest Endosc. 2006; 64:167-175. [PubMed: 16860063]

146. Kara MA, Ennahachi M, Fockens P, et al. Detection and classification of the mucosal and vascular patterns (mucosal morphology) in Barrett's esophagus by using narrow band imaging. Gastrointest Endosc. 2006; 64:155-166. [PubMed: 16860062]

147. Curvers W, Baak L, Kiesslich R, et al. Chromoendoscopy and narrow-band imaging compared with high-resolution magnification endoscopy in Barrett's esophagus. Gastroenterology. 2008; 134:670-679. [PubMed: 18242603]

148. Wolfsen HC, Crook JE, Krishna M, et al. Prospective, controlled tandem endoscopy study of narrow band imaging for dysplasia detection in Barrett's esophagus. Gastroenterology. 2008; 135:24-31. [PubMed: 18442484]

149. Sharma P, Bansal A, Hawes R, et al. Detection of metaplasia and neoplasia in patients with Barrett's esophagus using high-definition white light endoscopy versus narrow band imaging: a prospective, multi-center, randomized, crossover trial. Gastrointest Endosc. 2009; 69:AB135.

150. Kara MA, Peters FP, ten Kate FJW, et al. Endoscopic video autofluorescence imaging may improve the detection of early neoplasia in patients with Barrett's esophagus. Gastrointest Endosc. 2005; 61:679-685. [PubMed: 15855971] 
151. Kara MA, Peters FP, Fockens P, et al. Endoscopic video-autofluorescence imaging followed by narrow band imaging for detecting early neoplasia in Barrett's esophagus. Gastrointest Endosc. 2006; 64:176-185. [PubMed: 16860064]

152. Curvers WL, Singh R, Wong Kee Song LM, et al. Endoscopic tri-modal imaging for detection of early neoplasia in Barrett's oesophagus; a multi-centre feasibility study using high-resolution endoscopy, autofluorescence imaging and narrow band imaging incorporated in one endoscopy system. Gut. 2008; 57:167-172. [PubMed: 17965067]

153. Kiesslich R, Gossner L, Goetz M, et al. In vivo histology of Barrett's esophagus and associated neoplasia by confocal laser endomicroscopy. Clin Gastroenterol Hepatol. 2006; 4:979-987. [PubMed: 16843068]

154. Pohl H, Rosch T, Vieth M, et al. Miniprobe confocal laser microscopy for the detection of invisible neoplasia in patients with Barrett's esophagus. Gut. 2008; 57:1648-1653. [PubMed: 18755886]

155. Meining A, Saur D, Bajbouj M, et al. In vivo histopathology for detection of gastrointestinal neoplasia with a portable, confocal miniprobe: an examiner blinded analysis. Clin Gastroenterol Hepatol. 2007; 5:1261-1267. [PubMed: 17689297]

156. Kiesslich R, Burg J, Vieth M, et al. Confocal laser endoscopy for diagnosing intraepithelial neoplasias and colorectal cancer in vivo. Gastroenterology. 2004; 127:706-713. [PubMed: 15362025]

157. Polglase AL, McLaren WJ, Skinner SA, et al. A fluorescence confocal endomicroscope for in vivo microscopy of the upper- and the lower-GI tract. Gastrointest Endosc. 2005; 62:686-695. [PubMed: 16246680]

158. Becker V, Vercauteren T, von Weyhern $\mathrm{CH}$, et al. High-resolution miniprobe-based confocal microscopy in combination with video mosaicing (with video). Gastrointest Endosc. 2007; 66:1001-1007. [PubMed: 17767932]

159. Kumagai Y, Monma K, Kawada K. Magnifying chromoendoscopy of the esophagus: in-vivo pathological diagnosis using an endocytoscopy system. Endoscopy. 2004; 36:590-594. [PubMed: 15243880]

160. Pohl H, Koch M, Khalifa A, et al. Evaluation of endocytoscopy in the surveillance of patients with Barrett's esophagus. Endoscopy. 2007; 39:492-496. [PubMed: 17554642]

161. Georgakoudi I, Jacobson B, Van Dam J, et al. Fluorescence, reflectance and light scattering spectroscopy for evaluating dysplasia in patients with Barrett's esophagus. Gastroenterology. 2001; 120:1620-1629. [PubMed: 11375944]

162. Ortner MA, Ebert B, Hein E, et al. Time gated fluorescence spectroscopy in Barrett's oesophagus. Gut. 2003; 52:28-33. [PubMed: 12477755]

163. Wallace MB, Perelman LT, Backman V, et al. Endoscopic detection of dysplasia in patients with Barrett's esophagus using light-scattering spectroscopy. Gastroenterology. 2000; 119:677-682. [PubMed: 10982761]

164. Kobayashi K, Izatt JA, Kulkarni MD, et al. High-resolution cross-sectional imaging of the gastrointestinal tract using optical coherence tomography: preliminary results. Gastrointest Endosc. 1998; 47:515-523. [PubMed: 9647378]

165. Bouma BE, Tearney GJ, Compton CC, et al. High-resolution imaging of the human esophagus and stomach in vivo using optical coherence tomography. Gastrointest Endosc. 2000; 51:467474. [PubMed: 10744824]

166. Poneros JM, Brand S, Bouma BE, et al. Diagnosis of specialized metaplasia by optical coherence tomography. Gastroenterology. 2001; 120:7-12. [PubMed: 11208708]

167. Evans JA, Poneros JM, Bouma BE, et al. Optical coherence tomography to identify intramucosal carcinoma and high-grade dysplasia in Barrett's esophagus. Clin Gastroenterol Hepatol. 2006; 4:38-43. [PubMed: 16431303]

168. Qi X, Sivak MV, Isenberg G, et al. Computer-aided diagnosis of dysplasia in Barrett's esophagus using endoscopic optical coherence tomography. J Biomed Opt. 2006; 11:044010. [PubMed: 16965167] 
169. Kelloff GJ, Lippman SM, Dannenberg AJ, et al. Progress in chemoprevention drug development: the promise of molecular biomarkers for prevention of intraepithelial neoplasia and cancer--a plan to move forward. Clin Cancer Res. 2006; 12:3661-3697. [PubMed: 16778094]

170. Fitzgerald RC, Omary MB, Triadafilopoulos G. Dynamic effects of acid on Barrett's esophagus. An ex vivo proliferation and differentiation model. J Clin Invest. 1996; 98:2120-2128. [PubMed: 8903332]

171. Shirvani VN, Ouatu-Lascar R, Kaur BS, et al. Cyclooxygenase 2 expression in Barrett's Esophagus and adenocarcinoma: ex vivo induction by bile salts and acid exposure. Gastroenterology. 2000; 118:487-496. [PubMed: 10702199]

172. Souza RF, Shewmake K, Terada LS, et al. Acid exposure activates the mitogen-activated protein kinase pathways in Barrett's esophagus. Gastroenterology. 2002; 122:299-307. [PubMed: 11832445]

173. Clemons NJ, McColl KE, Fitzgerald RC. Nitric oxide and acid induce double-strand DNA breaks in Barrett's esophagus carcinogenesis via distinct mechanisms. Gastroenterology. 2007; 133:1198-1209. [PubMed: 17919494]

174. El Serag HB, Aguirre TV, Davis S, et al. Proton pump inhibitors are associated with reduced incidence of dysplasia in Barrett's esophagus. Am J Gastroenterol. 2004; 99:1877-1883. [PubMed: 15447744]

175. Hillman LC, Chiragakis L, Shadbolt B, et al. Proton-pump inhibitor therapy and the development of dysplasia in patients with Barrett's oesophagus. Med J Aust. 2004; 180:387-391. [PubMed: 15089728]

176. Cooper BT, Chapman W, Neumann CS, et al. Continuous treatment of Barrett's oesophagus patients with proton pump inhibitors up to 13 years: observations on regression and cancer incidence. Aliment Pharmacol Ther. 2006; 23:727-733. [PubMed: 16556174]

177. Nguyen DM, El Serag HB, Henderson L, et al. Medication usage and the risk of neoplasia in patients with Barrett's esophagus. Clin Gastroenterol Hepatol. 2009; 7:1299-1304. [PubMed: 19523538]

178. Ouatu-Lascar R, Fitzgerald RC, Triadafilopoulos G. Differentiation and proliferation in Barrett's esophagus and the effects of acid suppression. Gastroenterology. 1999; 117:327-335. [PubMed: 10419913]

179. Peters FT, Ganesh S, Kuipers EJ, et al. Effect of elimination of acid reflux on epithelial cell proliferative activity of Barrett esophagus. Scand J Gastroenterol. 2000; 35:1238-1244. [PubMed: 11199360]

180. Umansky M, Yasui W, Hallak A, et al. Proton pump inhibitors reduce cell cycle abnormalities in Barrett's esophagus. Oncogene. 2001; 20:7987-7991. [PubMed: 11753681]

181. García Rodríguez LA, Lagergren J, Lindblad M. Gastric acid suppression and risk of oesophageal and gastric adenocarcinoma: a nested case control study in the UK. Gut. 2006; 55:1538-1544. [PubMed: 16785284]

182. Chow WH, Findkle WD, McLaughlin JK, et al. The relation of gastroesophageal reflux disease and its treatment to adenocarcinomas of the esophagus and gastric cardia. JAMA. 1995; 274:474-477. [PubMed: 7629956]

183. Garrow DC, Vaughan TL, Sweeney C, et al. Gastroesophageal reflux disease, use of $\mathrm{H} 2$ receptor antagonists, and risk of esophageal and gastric cancer. Cancer Causes Control. 2000; 11:231238. [PubMed: 10782657]

184. Molina MA, Sitja-Arnau M, Lemoine MG, et al. Increased cyclooxygenase-2 expression in human pancreatic carcinomas and cell lines: growth inhibition by nonsteroidal anti-inflammatory drugs. Cancer Res. 1999; 59:4356-4362. [PubMed: 10485483]

185. Piazza GA, Rahm AL, Krutzsch M, et al. Antineoplastic drugs sulindac sulfide and sulfone inhibit cell growth by inducing apoptosis. Cancer Res. 1995; 55:3110-3116. [PubMed: 7606732]

186. Souza RF, Shewmake K, Beer DG, et al. Selective inhibition of cyclooxygenase-2 suppresses growth and induces apoptosis in human esophageal adenocarcinoma cells. Cancer Research. 2000; 60:5767-5772. [PubMed: 11059772] 
187. Buttar NS, Wang KK, Anderson MA, et al. The effect of selective cyclooxygenase-2 inhibition in Barrett's esophagus epithelium: an in vitro study. J Natl Cancer Inst. 2002; 94:422-429. [PubMed: 11904314]

188. Aggarwal S, Taneja N, Lin L, et al. Indomethacin-induced apoptosis in esophageal adenocarcinoma cells involves upregulation of Bax and translocation of mitochondrial cytochrome C independent of COX-2 expression. Neoplasia. 2000; 2:346-356. [PubMed: 11005569]

189. von Rahden BH, Stein HJ, Puhringer F, et al. Coexpression of cyclooxygenases (COX-1, COX-2) and vascular endothelial growth factors (VEGF-A, VEGF-C) in esophageal adenocarcinoma. Cancer Res. 2005; 65:5038-5044. [PubMed: 15958546]

190. Buttar NS, Wang KK, Leontovich O, et al. Chemoprevention of esophageal adenocarcinoma by COX-2 inhibitors in an animal model of Barrett's esophagus. Gastroenterology. 2002; 122:11011112. [PubMed: 11910360]

191. Oyama K, Fujimura T, Ninomiya I, et al. A COX-2 inhibitor prevents the esophageal inflammation-metaplasia-adenocarcinoma sequence in rats. Carcinogenesis. 2005; 26:565-570. [PubMed: 15564290]

192. Kim SW, Jang TJ, Jung KH, et al. Sulindac prevents esophageal adenocarcinomas induced by gastroduodenal reflux in rats. Yonsei Med J. 2007; 48:1020-1027. [PubMed: 18159596]

193. Kaur BS, Khamnehei N, Iravani M, et al. Rofecoxib inhibits cyclooxygenase 2 expression and activity and reduces cell proliferation in Barrett's esophagus. Gastroenterology. 2002; 123:60-67. [PubMed: 12105834]

194. Corley DA, Kerlikowske K, Verma R, et al. Protective association of aspirin/NSAIDs and esophageal cancer: a systematic review and meta-analysis. Gastroenterology. 2003; 124:47-56. [PubMed: 12512029]

195. Abnet CC, Freedman ND, Kamangar F, et al. Non-steroidal anti-inflammatory drugs and risk of gastric and oesophageal adenocarcinomas: results from a cohort study and a meta-analysis. $\mathrm{Br} \mathrm{J}$ Cancer. 2009; 100:551-557. [PubMed: 19156150]

196. Vaughan TL, Dong LM, Blount PL, et al. Non-steroidal anti-inflammatory drugs and risk of neoplastic progression in Barrett's oesophagus: a prospective study. Lancet Oncol. 2005; 6:945952. [PubMed: 16321762]

197. Heath EI, Canto MI, Piantadosi S, et al. Secondary chemoprevention of Barrett's esophagus with celecoxib: results of a randomized trial. J Natl Cancer Inst. 2007; 99:545-557. [PubMed: 17405999]

198. McQuaid KR, Laine L. Systematic review and meta-analysis of adverse events of low-dose aspirin and clopidogrel in randomized controlled trials. Am J Med. 2006; 119:624-638. [PubMed: 16887404]

199. Chan FK, Chung SC, Suen BY, et al. Preventing recurrent upper gastrointestinal bleeding in patients with Helicobacter pylori infection who are taking low-dose aspirin or naproxen. N Engl J Med. 2001; 344:967-973. [PubMed: 11274623]

200. Lai KC, Lam SK, Chu KM, et al. Lansoprazole for the prevention of recurrences of ulcer complications from long-term low-dose aspirin use. N Engl J Med. 2003; 346:2033-2038. [PubMed: 12087138]

201. Antithrombotic Trialists' Collaboration. Collaborative meta-analysis of randomised trials of antiplatelet therapy for prevention of death, myocardial infarction, and stroke in high risk patients. BMJ. 2002; 324:71-86. [PubMed: 11786451]

202. Hayden M, Pignone M, Phillips C, et al. Aspirin for the primary prevention of cardiovascular events: a summary of the evidence for the U.S. Preventive Services Task Force. Ann Intern Med. 2002; 136:161-172. [PubMed: 11790072]

203. Das D, Chilton AP, Jankowski JA. Chemoprevention of oesophageal cancer and the AspECT trial. Recent Results Cancer Res. 2009; 181:161-169. [PubMed: 19213566]

204. Katzka DA, Castell DO. Successful elimination of reflux symptoms does not ensure adequate control of acid reflux in patients with Barrett's esophagus. Am J Gastroenterol. 1994; 89:989991. [PubMed: 8017396] 
205. Yeh RW, Gerson LB, Triadafilopoulos G. Efficacy of esomeprazole in controlling reflux symptoms, intraesophageal, and intragastric $\mathrm{pH}$ in patients with Barrett's esophagus. Dis Esophagus. 2003; 16:193-198. [PubMed: 14641308]

206. Gerson LB, Boparai V, Ullah N, et al. Oesophageal and gastric $\mathrm{pH}$ profiles in patients with gastro-oesophageal reflux disease and Barrett's oesophagus treated with proton pump inhibitors. Aliment Pharmacol Ther. 2004; 20:637-643. [PubMed: 15352912]

207. DeMeester SR, DeMeester TR. Columnar mucosa and intestinal metaplasia of the esophagus. Fifty years of controversy. Ann Surg. 2000; 231:303-321. [PubMed: 10714623]

208. McCallum RW, Polepalle S, Davenport K, et al. Role of anti-reflux surgery against dysplasia in Barrett's esophagus (abstr). Gastroenterology. 1991; 100:A121.

209. Katz D, Rothstein R, Schned A, et al. The development of dysplasia and adenocarcinoma during endoscopic surveillance of Barrett's esophagus. Am J Gastroenterol. 1998; 93:536-541. [PubMed: 9576444]

210. Oberg S, Wenner J, Johansson J, et al. Barrett esophagus: risk factors for progression to dysplasia and adenocarcinoma. Ann Surg. 2005; 242:49-54. [PubMed: 15973101]

211. Spechler SJ, Lee E, Ahnen D, et al. Long-term outcome of medical and surgical treatments for gastroesophageal reflux disease. Follow-up of a randomized controlled trial. JAMA. 2001; 285:2331-2338. [PubMed: 11343480]

212. Ye W, Chow WH, Lagergren J, et al. Risk of adenocarcinoma of the esophagus and gastric cardia in patients with gastroesophageal reflux diseases and after antireflux surgery. Gastroenterology. 2001; 121:1286-1293. [PubMed: 11729107]

213. Tran T, Spechler SJ, El-Serag HB. Fundoplication and the risk of cancer in gastroesophageal reflux disease: a Veterans Affairs cohort study. Am J Gastroenterol. 2005; 100:1002-1008. [PubMed: 15842570]

214. Corey KE, Schmitz SM, Shaheen NJ. Does a surgical antireflux procedure decrease the incidence of esophageal adenocarcinoma in Barrett's esophagus? A meta-analysis. Am J Gastroenterol. 2003; 98:2390-2394. [PubMed: 14638338]

215. Li YM, Li L, Yu CH, et al. A systematic review and meta-analysis of the treatment for Barrett's esophagus. Dig Dis Sci. 2008; 53:2837-2846. [PubMed: 18427992]

216. Rice TW, Zuccaro G, Adelstein DJ, et al. Esophageal carcinoma: depth of tumor invasion is predictive of regional lymph node status. Ann Thorac Surg. 1998; 65:787-792. [PubMed: 9527214]

217. Feith M, Stein HJ, Siewert JR. Pattern of lymphatic spread of Barrett's cancer. World J Surg. 2003; 27:1052-1057. [PubMed: 12917758]

218. Oh DS, Hagen JA, Chandrasoma PT, et al. Clinical biology and surgical therapy of intramucosal adenocarcinoma of the esophagus. J Am Coll Surg. 2006; 203:152-161. [PubMed: 16864027]

219. Peyre CG, DeMeester SR, Rizzetto C, et al. Vagal-sparing esophagectomy: the ideal operation for intramucosal adenocarcinoma and Barrett with high-grade dysplasia. Ann Surg. 2007; 246:665671. [PubMed: 17893503]

220. Stein HJ, Feith M, Bruecher BL, et al. Early esophageal cancer: pattern of lymphatic spread and prognostic factors for long-term survival after surgical resection. Ann Surg. 2005; 242:566-573. [PubMed: 16192817]

221. Falk GW, Catalano MF, Sivak MV Jr, et al. Endosonography in the evaluation of patients with Barrett's esophagus and high-grade dysplasia. Gastrointest Endosc. 1994; 40:207-212. [PubMed: 8013823]

222. Waxman I, Raju GS, Critchlow J, et al. High frequency probe ultrasonography has limited accuracy for detecting invasive adenocarcinoma in patients with Barrett's esophagus and high grade dysplasia or intramucosal carcinoma: a case series. Am J Gastroenterol. 2006; 101:17731779. [PubMed: 16780561]

223. Larghi A, Lightdale CJ, Memeo L, et al. EUS followed by EMR for staging of high-grade dysplasia and early cancer in Barrett's esophagus. Gastrointest Endosc. 2005; 62:16-23. [PubMed: 15990814] 
224. Prasad GA, Buttar NS, Wongkeesong LM, et al. Significance of neoplastic involvement of margins obtained by endoscopic mucosal resection in Barrett's esophagus. Am J Gastroenterol. 2007; 102:2380-2386. [PubMed: 17640326]

225. Giovannini M, Bories E, Pesenti C, et al. Circumferential endoscopic mucosal resection in Barrett's esophagus with high-grade intraepithelial neoplasia or mucosal cancer. Preliminary results in 21 patients. Endoscopy. 2004; 36:782-787. [PubMed: 15326573]

226. Seewald S, Akaraviputh T, Seitz U, et al. Circumferential EMR and complete removal of Barrett's epithelium: a new approach to management of Barrett's esophagus containing high-grade intraepithelial neoplasia and intramucosal carcinoma. Gastrointest Endosc. 2003; 57:854-859. [PubMed: 12776032]

227. Peters FP, Kara MA, Rosmolen WD, et al. Stepwise radical endoscopic resection is effective for complete removal of Barrett's esophagus with early neoplasia: a prospective study. Am J Gastroenterol. 2006; 101:1449-1457. [PubMed: 16863545]

228. Conio M, Repici A, Cestari R, et al. Endoscopic mucosal resection for high-grade dysplasia and intramucosal carcinoma in Barrett's esophagus: an Italian experience. World J Gastroenterol. 2005; 11:6650-6655. [PubMed: 16425359]

229. Soehendra N, Seewald S, Groth S, et al. Use of modified multiband ligator facilitates circumferential EMR in Barrett's esophagus (with video). Gastrointest Endosc. 2006; 63:847852. [PubMed: 16650552]

230. Larghi A, Lightdale CJ, Ross AS, et al. Long-term follow-up of complete Barrett's eradication endoscopic mucosal resection (CBE-EMR) for the treatment of high grade dysplasia and intramucosal carcinoma. Endoscopy. 2007; 39:1086-1091. [PubMed: 17701854]

231. Lopes CV, Hela M, Pesenti C, et al. Circumferential endoscopic resection of Barrett's esophagus with high-grade dysplasia or early adenocarcinoma. Surg Endosc. 2007; 21:820-824. [PubMed: 17294308]

232. Pech O, Behrens A, May A, et al. Long-term results and risk factor analysis for recurrence after curative endoscopic therapy in 349 patients with high-grade intraepithelial neoplasia and mucosal adenocarcinoma in Barrett's oesophagus. Gut. 2008; 57:1200-1206. [PubMed: 18460553]

233. Montes CG, Brandalise NA, Deliza R, et al. Antireflux surgery followed by bipolar electrocoagulation in the treatment of Barrett's esophagus. Gastrointest Endosc. 1999; 50:173177. [PubMed: 10425408]

234. Sampliner RE, Faigel D, Fennerty MB, et al. Effective and safe endoscopic reversal of nondysplastic Barrett's esophagus with thermal electrocoagulation combined with high-dose acid inhibition: a multicenter study. Gastrointest Endosc. 2001; 53:554-558. [PubMed: 11323578]

235. Sharma P, Wani S, Weston AP, et al. A randomised controlled trial of ablation of Barrett's oesophagus with multipolar electrocoagulation versus argon plasma coagulation in combination with acid suppression: long term results. Gut. 2006; 55:1233-1239. [PubMed: 16905695]

236. Dulai GS, Jensen DM, Cortina G, et al. Randomized trial of argon plasma coagulation vs. multipolar electrocoagulation for ablation of Barrett's esophagus. Gastrointest Endosc. 2005; 61:232-240. [PubMed: 15729231]

237. Madisch A, Miehlke S, Bayerdorffer E, et al. Long-term follow-up after complete ablation of Barrett's esophagus with argon plasma coagulation. World J Gastroenterol. 2005; 11:1182-1186. [PubMed: 15754401]

238. Mork H, Al-Taie O, Berlin F, et al. High recurrence rate of Barrett's epithelium during long-term follow-up after argon plasma coagulation. Scand J Gastroenterol. 2007; 42:23-27. [PubMed: 17190758]

239. Kelty CJ, Ackroyd R, Brown NJ, et al. Endoscopic ablation of Barrett's oesophagus: a randomized-controlled trial of photodynamic therapy vs. argon plasma coagulation. Aliment Pharmacol Ther. 2004; 20:1289-1296. [PubMed: 15606390]

240. Bright T, Watson DI, Tam W, et al. Prospective randomized trial of argon plasma coagulation ablation versus endoscopic surveillance of Barrett's esophagus in patients treated with antisecretory medication. Dig Dis Sci. Dec 20.2008 Epub ahead of print. 
241. Sharma VK, Wang KK, Overholt BF, et al. Balloon-based, circumferential, endoscopic radiofrequency ablation of Barrett's esophagus: 1-year follow-up of 100 patients. Gastrointest Endosc. 2007; 65:185-195. [PubMed: 17258973]

242. Fleischer DE, Overholt BF, Sharma VK, et al. Endoscopic ablation of Barrett's esophagus: a multicenter study with 2.5-year follow-up. Gastrointest Endosc. 2008; 68:867-876. [PubMed: 18561930]

243. Manner H, May A, Miehlke S, et al. Ablation of nonneoplastic Barrett's mucosa using argon plasma coagulation with concomitant esomeprazole therapy (APBANEX): a prospective multicenter evaluation. Am J Gastroenterol. 2006; 101:1762-1769. [PubMed: 16817835]

244. Inadomi JM, Somsouk M, Madanick RD, et al. A cost-utility analysis of ablative therapy for Barrett's esophagus. Gastroenterology. 2009; 136:2101-2114. [PubMed: 19272389]

245. Familiari L, Scaffidi M, Bonica M, et al. Endoscopic treatment of Barrett's epithelium with argon plasma coagulation. Long-term follow-up. Minerva Gastroenterol Dietol. 2003; 49:63-70. [PubMed: 16481972]

246. Ackroyd R, Kelty CJ, Brown NJ, et al. Eradication of dysplastic Barrett's oesophagus using photodynamic therapy: long-term follow-up. Endoscopy. 2003; 35:496-501. [PubMed: 12783347]

247. Overholt BF, Panjehpour M, Halberg DL. Photodynamic therapy for Barrett's esophagus with dysplasia and/or early stage carcinoma: long-term results. Gastrointest Endosc. 2003; 58:183188. [PubMed: 12872083]

248. Ragunath K, Krasner N, Raman VS, et al. Endoscopic ablation of dysplastic Barrett's oesophagus comparing argon plasma coagulation and photodynamic therapy: a randomized prospective trial assessing efficacy and cost-effectiveness. Scand J Gastroenterol. 2005; 40:750-758. [PubMed: 16118910]

249. Sharma VK, Kim JH, Das A, et al. Circumferential and focal ablation of Barrett's esophagus containing dysplasia. Am J Gastroenterol. 2009; 104:310-317. [PubMed: 19174783]

250. Shaheen NJ, Sharma P, Overholt BF, et al. Radiofrequency ablation in Barrett's esophagus with dysplasia. N Engl J Med. 2009; 360:2277-2288. [PubMed: 19474425]

251. Peters FP, Kara MA, Rosmolen WD, et al. Stepwise radical endoscopic resection is effective for complete removal of Barrett's esophagus with early neoplasia: a prospective study. Am J Gastroenterol. 2006; 101:1449-1457. [PubMed: 16863545]

252. Overholt BF, Lightdale CJ, Wang KK, et al. Photodynamic therapy with porfimer sodium for ablation of high-grade dysplasia in Barrett's esophagus: international, partially blinded, randomized phase III trial. Gastrointest Endosc. 2005; 62:488-498. [PubMed: 16185958]

253. Overholt BF, Wang KK, Burdick JS, et al. Five-year efficacy and safety of photodynamic therapy with Photofrin in Barrett's high-grade dysplasia. Gastrointest Endosc. 2007; 66:460-468. [PubMed: 17643436]

254. Gossner L, Stolte M, Sroka R, et al. Photodynamic ablation of high-grade dysplasia and early cancer in Barrett's esophagus by means of 5-aminolevulinic acid. Gastroenterology. 1998; 114:448-455. [PubMed: 9496934]

255. Pech O, Gossner L, May A, et al. Long-term results of photodynamic therapy with 5aminolevulinic acid for superficial Barrett's cancer and high-grade intraepithelial neoplasia. Gastrointest Endosc. 2005; 62:24-30. [PubMed: 15990815]

256. Ganz RA, Overholt BF, Sharma VK, et al. Circumferential ablation of Barrett's esophagus that contains high-grade dysplasia a U.S. multicenter registry. Gastrointest Endosc. 2008; 68:35-40. [PubMed: 18355819]

257. Johnston M, Eastone JA, Horwat JD, et al. Cryoablation of Barrett's esophagus: a pilot study. Gastrointest Endosc. 2005; 62:842-848. [PubMed: 16301023]

258. Dumot JA, Vargo JJ II, Falk GW, et al. An open-label, prospective trial of cryospray ablation for Barrett's esophagus high-grade dysplasia and early esophageal cancer in high-risk patients. Gastrointest Endosc. 2009; 70:635-644. [PubMed: 19559428]

259. Attwood SE, Lewis CJ, Caplin S, et al. Argon beam plasma coagulation as therapy for high-grade dysplasia in Barrett's esophagus. Clin Gastroenterol Hepatol. 2003; 1:258-263. [PubMed: 15017666] 
260. Pouw RE, Wirths K, Eisendrath P, et al. Efficacy of radiofrequency ablation combined with endoscopic resection for Barrett's esophagus with early neoplasia. Clin Gastroenterol Hepatol. 2010; 8:23-29. [PubMed: 19602454]

261. Wani S, Sayana H, Sharma P. Endoscopic eradication of Barrett's esophagus. Gastrointest Endosc. 2010; 71:147-166. [PubMed: 19879565]

262. Bronner MP, Overholt BF, Taylor SL. International Photodynamic Therapy Group for HighGrade Dysplasia in Barrett's Esophagus. Squamous overgrowth is not a safety concern for photodynamic therapy for Barrett's esophagus with high-grade dysplasia. Gastroenterology. 2009; 136:56-64. [PubMed: 18996379]

263. Wani S, Puli SR, Shaheen NJ, et al. Esophageal adenocarcinoma in Barrett's esophagus after endoscopic ablative therapy: a meta-analysis and systematic review. Am J Gastroenterol. 2009; 104:502-513. [PubMed: 19174812]

264. Meguid RA, Weiss ES, Chang DC, et al. The effect of volume on esophageal cancer resections: what constitutes acceptable resection volumes for centers of excellence? J Thorac Cardiovasc Surg. 2009; 137:23-29. [PubMed: 19154895]

265. Van Lanschot JJB, Hulscher JBF, Buskens CJ, et al. Hospital volume and hospital mortality for esophagectomy. Cancer. 2001; 91:1574-1578. [PubMed: 11301408]

266. Dimick JB, Pronovost PJ, Cowan JA, et al. Surgical volume and quality of care for esophageal resection: Do high-volume hospitals have fewer complications? Ann Thorac Surg. 2003; 75:337341. [PubMed: 12607635]

267. Dimick JB, Cattaneo SM, Lipsett PA, et al. Hospital volume is related to clinical and economic outcomes of esophageal resection in Maryland. Ann Thorac Surg. 2001; 72:334-341. [PubMed: 11515862]

268. Begg CB, Cramer LD, Hoskins WJ, et al. Impact of hospital volume on operative mortality for major cancer surgery. JAMA. 1998; 280:1747-1751. [PubMed: 9842949]

269. Patti MG, Corvera CU, Glasgow RE, et al. A hospital's annual rate of esophagectomy influences the operative mortality rate. J Gastrointest Surg. 1998; 2:186-192. [PubMed: 9834415]

270. Birkmeyer JD, Siewers AE, Finlayson EVA, et al. Hospital volume and surgical mortality in the United States. N Engl J Med. 2002; 346:1128-1137. [PubMed: 11948273]

271. Prasad GA, Wu TT, Wigle DA, et al. Endoscopic and surgical treatment of mucosal (T1a) esophageal adenocarcinoma in Barrett's esophagus. Gastroenterology. 2009; 137:815-823. [PubMed: 19524578]

272. Wang VS, Hornick JL, Sepulveda JA, et al. Low prevalence of submucosal invasive carcinoma at esophagectomy for high-grade dysplasia or intramucosal adenocarcinoma in Barrett's esophagus: a 20-year experience. Gastrointest Endosc. 2009; 69:777-783. [PubMed: 19136106]

273. Altorki NK, Lee PC, Liss Y, et al. Multifocal neoplasia and nodal metastases in T1 esophageal carcinoma: implications for endoscopic treatment. Ann Surg. 2008; 247:434-439. [PubMed: 18376186]

274. Schembre DB, Huang JL, Lin OS, et al. Treatment of Barrett's esophagus with early neoplasia: a comparison of endoscopic therapy and esophagectomy. Gastrointest Endosc. 2008; 67:595-601. [PubMed: 18279860]

275. Munítiz V, Martínez de Haro LF, Ortiz MA, et al. Surgical treatment of high-grade dysplasia in Barrett's esophagus. Cir Esp. 2007; 82:214-218. [PubMed: 17942046]

276. Williams VA, Watson TJ, Herbella FA, et al. Esophagectomy for high grade dysplasia is safe, curative, and results in good alimentary outcome. J Gastrointest Surg. 2007; 11:1589-1597. [PubMed: 17909921]

277. Peyre CG, DeMeester SR, Rizzetto C, et al. Vagal-sparing esophagectomy: the ideal operation for intramucosal adenocarcinoma and Barrett with high-grade dysplasia. Ann Surg. 2007; 246:665671. [PubMed: 17893503]

278. Moraca RJ, Low DE. Outcomes and health-related quality of life after esophagectomy for highgrade dysplasia and intramucosal cancer. Arch Surg. 2006; 141:545-549. [PubMed: 16785354]

279. Chang LC, Oelschlager BK, Quiroga E, et al. Long-term outcome of esophagectomy for highgrade dysplasia or cancer found during surveillance for Barrett's esophagus. J Gastrointest Surg. 2006; 10:341-346. [PubMed: 16504878] 
280. Sujendran V, Sica G, Warren B, et al. Oesophagectomy remains the gold standard for treatment of high-grade dysplasia in Barrett's oesophagus. Eur J Cardiothorac Surg. 2005; 28:763-766. [PubMed: 16188449]

281. Reed MF, Tolis G Jr, Edil BH, et al. Surgical treatment of esophageal high-grade dysplasia. Ann Thorac Surg. 2005; 79:1110-1115. [PubMed: 15797034]

282. Pacifico RJ, Wang KK, Wongkeesong LM, et al. Combined endoscopic mucosal resection and photodynamic therapy versus esophagectomy for management of early adenocarcinoma in Barrett's esophagus. Clin Gastroenterol Hepatol. 2003; 1:252-257. [PubMed: 15017665]

283. Heitmiller RF. Prophylactic esophagectomy in Barrett esophagus with high-grade dysplasia. Langenbecks Arch Surg. 2003; 388:83-87. [PubMed: 12712340]

284. Thomson BN, Cade RJ. Oesophagectomy for early adenocarcinoma and dysplasia arising in Barrett's oesophagus. ANZ J Surg. 2003; 73:121-124. [PubMed: 12608973]

285. Tseng EE, Wu TT, Yeo CJ, et al. Barrett's esophagus with high grade dysplasia: surgical results and long-term outcome\&mdash;an update. J Gastrointest Surg. 2003; 7:164-170. [PubMed: 12600440]

286. Perry Y, Fernando HC, Buenaventura PO, et al. Minimally invasive esophagectomy in the elderly. JSLS. 2002; 6:299-304. [PubMed: 12500826]

287. Scott Bolton J, Wu TT, Yeo CJ, et al. Esophagectomy for adenocarcinoma in patients 45 years of age and younger. J Gastrointest Surg. 2001; 5:620-625. [PubMed: 12086900]

288. Headrick JR, Nichols FC III, Miller DL, et al. High-grade esophageal dysplasia: long-term survival and quality of life after esophagectomy. Ann Thorac Surg. 2002; 73:1697-1702. [PubMed: 12078755]

289. Zaninotto G, Parenti AR, Ruol A, et al. Oesophageal resection for high-grade dysplasia in Barrett's oesophagus. Br J Surg. 2000; 87:1102-1105. [PubMed: 10931058]

290. Nguyen NT, Schauer P, Luketich JD. Minimally invasive esophagectomy for Barrett's esophagus with high-grade dysplasia. Surgery. 2000; 127:284-290. [PubMed: 10715983]

291. Catrambone G, Leoncini G, Iurilli L, et al. Complications of Barrett's esophagus: indications for esophageal resection with special reference to high-grade dysplasia. Minerva Chir. 1999; 54:657-667. [PubMed: 10575887]

292. Patti MG, Arcerito M, Feo CV, et al. Barrett's esophagus: a surgical disease. J Gastrointest Surg. 1999; 3:397-403. [PubMed: 10482692]

293. Luketich JD, Nguyen NT, Weigel T, et al. Minimally invasive approach to esophagectomy. JSLS. 1998; 2:243-247. [PubMed: 9876747]

294. Hölscher AH, Bollschweiler E, Schneider PM, et al. Early adenocarcinoma in Barrett's oesophagus. Br J Surg. 1997; 84:1470-1473. [PubMed: 9361616]

295. Heitmiller RF, Redmond M, Hamilton SR. Barrett's esophagus with high-grade dysplasia. An indication for prophylactic esophagectomy. Ann Surg. 1996; 224:66-71. [PubMed: 8678620]

296. Edwards MJ, Gable DR, Lentsch AB, et al. The rationale for esophagectomy as the optimal therapy for Barrett's esophagus with high-grade dysplasia. Ann Surg. 1996; 223:585-589. [PubMed: 8651749]

297. Rusch VW, Levine DS, Haggitt R, et al. The management of high grade dysplasia and early cancer in Barrett's esophagus. A multidisciplinary problem. Cancer. 1994; 74:1225-1229. [PubMed: 8055442]

298. Lerut T, Coosemans W, Van Raemdonck D, et al. Surgical treatment of Barrett's carcinoma. Correlations between morphologic findings and prognosis. J Thorac Cardiovasc Surg. 1994; 107:1059-1065. [PubMed: 8159027]

299. Rice TW, Falk GW, Achkar E, et al. Surgical management of high-grade dysplasia in Barrett's esophagus. Am J Gastroenterol. 1993; 88:1832-1836. [PubMed: 8237928]

300. Pera M, Trastek VF, Carpenter HA, et al. Barrett's esophagus with high-grade dysplasia: an indication for esophagectomy? Ann Thorac Surg. 1992; 54:199-204. [PubMed: 1637206]

301. Parameswaran R, McNair A, Avery KN, et al. The role of health-related quality of life outcomes in clinical decision making in surgery for esophageal cancer: a systematic review. Ann Surg Oncol. 2008; 15:2372-2379. [PubMed: 18626719] 
302. Safieddine N, Xu W, Quadri SM, et al. Health-related quality of life in esophageal cancer: effect of neoadjuvant hemoradiotherapy followed by surgical intervention. J Thorac Cardiovasc Surg. 2009; 137:36-42. [PubMed: 19154899]

303. van Meerten E, van der Gaast A, Looman CW, et al. Quality of life during neoadjuvant treatment and after surgery for resectable esophageal carcinoma. Int J Radiat Oncol Biol Phys. 2008; 71:160-166. [PubMed: 18164846]

304. de Boer AG, van Lanschot JJ, van Sandick JW, et al. Quality of life after transhiatal compared with extended transthoracic resection for adenocarcinoma of the esophagus. J Clin Oncol. 2004; 22:4202-4208. [PubMed: 15483031]

305. Blazeby JM, Farndon JR, Donovan J, et al. A prospective longitudinal study examining the quality of life of patients with esophageal carcinoma. Cancer. 2000; 88:1781-1787. [PubMed: 10760752]

306. Djärv T, Lagergren J, Blazeby JM, et al. Long-term health-related quality of life following surgery for oesophageal cancer. Br J Surg. 2008; 95:1121-1126. [PubMed: 18581441]

307. Avery KN, Metcalfe C, Barham CP, et al. Quality of life during potentially curative treatment for locally advanced oesophageal cancer. Br J Surg. 2007; 94:1369-1376. [PubMed: 17665422]

308. McLarty AJ, Deschamps C, Trastek VF, et al. Esophageal resection for cancer of the esophagus: long-term function and quality of life. Ann Thorac Surg. 1997; 63:1568-1572. [PubMed: 9205149]

309. Lagergren P, Avery KN, Hughes R, et al. Health-related quality of life among patients cured by surgery for esophageal cancer. Cancer. 2007; 110:686-693. [PubMed: 17582628]

310. De Boer AG, Genovesi PI, Sprangers MA, et al. Quality of life in long-term survivors after curative transhiatal oesophagectomy for esophageal carcinoma. Br J Surg. 2000; 87:1716-1721. [PubMed: 11122191]

311. Oberg S, Johansson J, Wenner J, et al. Metaplastic columnar mucosa in the cervical esophagus after esophagectomy. Ann Surg. 2002; 235:338-345. [PubMed: 11882755]

312. Dresner SM, Griffin SM, Wayman J, et al. Human model of duodenogastro-oesophageal reflux in the development of Barrett's metaplasia. Br J Surg. 2003; 90:1120-1128. [PubMed: 12945080]

313. Franchimont D, Covas A, Brasseur C, et al. Newly developed Barrett's esophagus after subtotal esophagectomy. Endoscopy. 2003; 35:850-853. [PubMed: 14551864]

314. O'Riordan JM, Tucker ON, Byrne PJ, et al. Factors influencing the development of Barrett's epithelium in the esophageal remnant postesophagectomy. Am J Gastroenterol. 2004; 99:205211. [PubMed: 15046206]

315. Lord RV, Wickramasinghe K, Johansson JJ, et al. Cardiac mucosa in the remnant esophagus after esophagectomy is an acquired epithelium with Barrett's-like features. Surgery. 2004; 136:633640. [PubMed: 15349112]

316. da Rocha JR, Ribeiro U Jr, Sallum RA, et al. Barrett's esophagus (BE) and carcinoma in the esophageal stump (ES) after esophagectomy with gastric pull-up in achalasia patients: a study based on 10 years follow-up. Ann Surg Oncol. 2008; 15:2903-2909. [PubMed: 18618179]

317. Gutschow CA, Vallböhmer D, Stolte M, et al. Adenocarcinoma developing in de novo Barrett's mucosa in the remnant esophagus after esophagectomy: clinical and molecular assessment. Dis Esophagus. 2008; 21:E6-E8. [PubMed: 18430096]

318. Wolfsen HC, Hemminger LL, DeVault KR. Recurrent Barrett's esophagus and adenocarcinoma after esophagectomy. BMC Gastroenterol. 2004; 4:18. [PubMed: 15327696] 